\title{
Expression sequence tag library derived from peripheral blood mononuclear cells of the chlorocebus sabaeus
}

\author{
Nicolas Tchitchek ${ }^{1 \dagger}$, Béatrice Jacquelin ${ }^{2 \dagger}$, Patrick Wincker ${ }^{3}$, Carole Dossat $^{3}$, Corinne Da Silva $^{3}$, \\ Jean Weissenbach ${ }^{3}$, Antoine Blancher ${ }^{4}$, Michaela Müller-Trutwin ${ }^{2 *}$ and Arndt Benecke ${ }^{1,5^{*}}$
}

\begin{abstract}
Background: African Green Monkeys (AGM) are amongst the most frequently used nonhuman primate models in clinical and biomedical research, nevertheless only few genomic resources exist for this species. Such information would be essential for the development of dedicated new generation technologies in fundamental and pre-clinical research using this model, and would deliver new insights into primate evolution.

Results: We have exhaustively sequenced an Expression Sequence Tag (EST) library made from a pool of Peripheral Blood Mononuclear Cells from sixteen Chlorocebus sabaeus monkeys. Twelve of them were infected with the Simian Immunodeficiency Virus. The mononuclear cells were or not stimulated in vitro with Concanavalin A, with lipopolysacharrides, or through mixed lymphocyte reaction in order to generate a representative and broad library of expressed sequences in immune cells. We report here 37,787 sequences, which were assembled into 14,410 contigs representing an estimated $12 \%$ of the C. sabaeus transcriptome. Using data from primate genome databases, 9,029 assembled sequences from C. sabaeus could be annotated. Sequences have been systematically aligned with ten cDNA references of primate species including Homo sapiens, Pan troglodytes, and Macaca mulatta to identify ortholog transcripts. For 506 transcripts, sequences were quasi-complete. In addition, 6,576 transcript fragments are potentially specific to the C. sabaeus or corresponding to not yet described primate genes.

Conclusions: The EST library we provide here will prove useful in gene annotation efforts for future sequencing of the African Green Monkey genomes. Furthermore, this library, which particularly well represents immunological and hematological gene expression, will be an important resource for the comparative analysis of gene expression in clinically relevant nonhuman primate and human research.
\end{abstract}

\section{Background}

Nonhuman primates (NHP) are used in many areas of biomedical research because of their close relationship to humans. Indeed, for some human diseases, such as for HCV and HIV infections, they still represent the only available animal model. Moreover, optimal drug safety assessment and vaccine development are in many instances dependent on NHPs. Nowadays, the knowledge of their genome and transcriptome becomes critical

\footnotetext{
*Correspondence: mmuller@pasteur.fr; arndt@ihes.fr

${ }^{\dagger}$ Equal Contributors

2 Institut Pasteur, Unité de Régulation des Infections Rétrovirales, Paris, France ${ }^{1}$ Institut des Hautes Études Scientifiques - Centre National de la Recherche

Scientifique, Bures-sur-Yvette, France

Full list of author information is available at the end of the article
}

for an efficient and parsimonious use of these models. The genome of the Chimpanzee (Pan troglodytes) [1], Indian rhesus macaque (Indian Macaca mulatta) [2], Orangutan (Pongo abelii [3], Chinese rhesus macaque (Chinese Macaca mulatta [4] and Cynomolgus macaque (Macaca fascicularis [4,5] have been sequenced, and sequencing of several other NHP genomes is ongoing [6,7]. The African Green Monkey (AGM) is a widely used species in biomedical research for studies in the field of immunology, neuroscience (such as Parkinson's disease $[8,9]$, cardiovascular disease [10], cell biology [11-13], pharmacology [14] and infectious diseases [15-19]. AGMs are one of the 40 natural hosts of the Simian Immunodeficiency Virus (SIV). They are particularly interesting 
models for studying of AIDS as this species is protected against the disease. Despite chronic infection by SIV, they generally do not develop any clinical symptoms $[19,20]$ and hence are used to identify correlates of protection [19-21]. AGMs are divided into four species, named vervet (Chlorocebus pygerythrus), grivet (Chlorocebus aethiops), sabaeus (Chlorocebus sabaeus) and tantalus (Chlorocebus tantalus). Among them, the vervet and sabaeus species have been most extensively studied [22-27]. Three hundred years ago, AGMs that belonged to the $C$. sabaeus species were transferred during slave trade from West/Central Africa to the Caribbean islands [28]. The only large breeding centers for AGMs are now located in these Islands, and the C. sabaeus species is now becoming the most studied AGM model for SIV and in biomedical research in general. In the context of viral infections such as with SIV, one of the main issues for the development of treatments and vaccines against human diseases, is to better understand the host transcriptomic responses of immune cells as the host immune response is mainly responsible for the outcome of the infection. Moreover, due to the important amount of genes expressed in case of activation, immune cells are relevant for revealing significant parts of the host transcriptome. So far, research involving AGMs, especially using gene expression profiling, were limited by the lack of sufficient gene sequence information and most studies were dependent on tools developed for human and more recently macaque species $[7,29,30]$. This limitation is a major problem since sequenced genes from AGMs revealed significant nucleotide differences from the human and even the macaque genomes [31-33], and more information on AGM gene sequences are therefore urgently needed. It should be noted however, that the difference between NHP and humans is higher at the level of which gene is expressed, rather than at the nucleotide diversity level [34]. In addition, it has been shown that NHP cells express additional genes that are not expressed in humans [35], and we have shown in a previous study that C. sabaeus express up to 16,000 genes in peripheral CD4+ cells, with 990 being specific of the species [36]. Annotating such sequences is challenging given that limited information is available and only few hundreds sequences of $C$. sabaeus are currently present in the GeneBank [37] database (Additional file 1: Figure S1). In this study, we constructed, sequenced and annotated a $C$. sabaeus EST (Expression Sequence Tag) library obtained from Peripheral Blood Mononuclear Cells (PBMC), as a tool for annotating AGM reference genomes, in order to allow the generation of technologies dedicated to analyze the immune responses in this species, as well as providing immediate valuable information to better understand the molecular and cellular mechanisms involved in AIDS resistance.

\section{Results \\ Composition and assembly of the Chlorocebus sabaeus PBMC EST library}

Our aim was to obtain the sequence information for the genes expressed in C. sabaeus immune cells. In order to be representative, we collected fresh PBMC from twelve SIV-infected and four non infected animals. In order to identify as many distinct transcripts as possible, we in vitro stimulated these cells or not with Concanavalin A (ConA), lipopolysaccharides (LPS) and by mixed lymphocyte reactions (MLR), as these stimuli upregulate mRNA expression of many genes. The different stimuli were chosen to activate distinct cellular receptors ( $\mathrm{T}$ cell receptor, Toll-like receptors) and stimulate distinct immune cells (lymphocytes and antigen-presenting cells). Total RNA preparations from the stimulated and unstimulated cells were pooled and a cDNA library constructed. Sequences were obtained and sequence quality filtering showed that 37,787 ESTs were present in the library. They had a mean length of 563 nucleotides per EST with a standard deviation of 167 nucleotides (Figure 1A). The 37,787 ESTs have been assembled into 3,853 contigs (overlapping or embedded ESTs) and 10,557 singletons (not assembled ESTs). The median number of ESTs per contig was 3 with some outlier contigs being composed of up to 941 ESTs (Figure 1B). The mean length of the 14,410 assembled and singletons ESTs averages at 943 nucleotides (Figure 1C). The total length represented by our AGM EST library is about $21.10^{6}$ nucleotides and the total length of the assembled distinct transcripts $9.10^{6}$ nucleotides. Since the total length of the known $M$. mulatta distinct transcripts corresponds to $72.10^{6}$ nucleotides in the Ensembl database [38], our AGM sequences represent $12 \%$ of the M. mulatta transcriptome and potentialy a similar fraction of the AGM transcriptome.

\section{Inter- and intra-species comparisons}

We then compared the ESTs to available transcriptomes of other primate species for annotation purposes and for quantification of transcript homologs. In order to get a general as well as a specific view, we used both the total 37,787 ESTs of the original library and the assembled distinct transcript library. They were aligned to available cDNA datasets of the following ten primate species: Callithrix jacchus (Ouistiti), Gorilla gorilla (Gorilla), Homo sapiens (Human), M. mulatta, Microcebus murinus (Mouse lemur), Nomascus leucogeny (Gibbon), Otolemur garnettii (Bushbaby), P. troglodytes, P. abelii, and Tarsuis syrichta (Tarsier) (Table 1). We applied stringent criteria for alignments. Thus, high-quality alignments have been filtered to only keep for each EST the best alignment for each species which maps at least $80 \%$ of the ESTs. 31,211 of the 37,787 total ESTs and 9,029 of the 14,410 assembled sequences could be aligned on cDNAs of at 

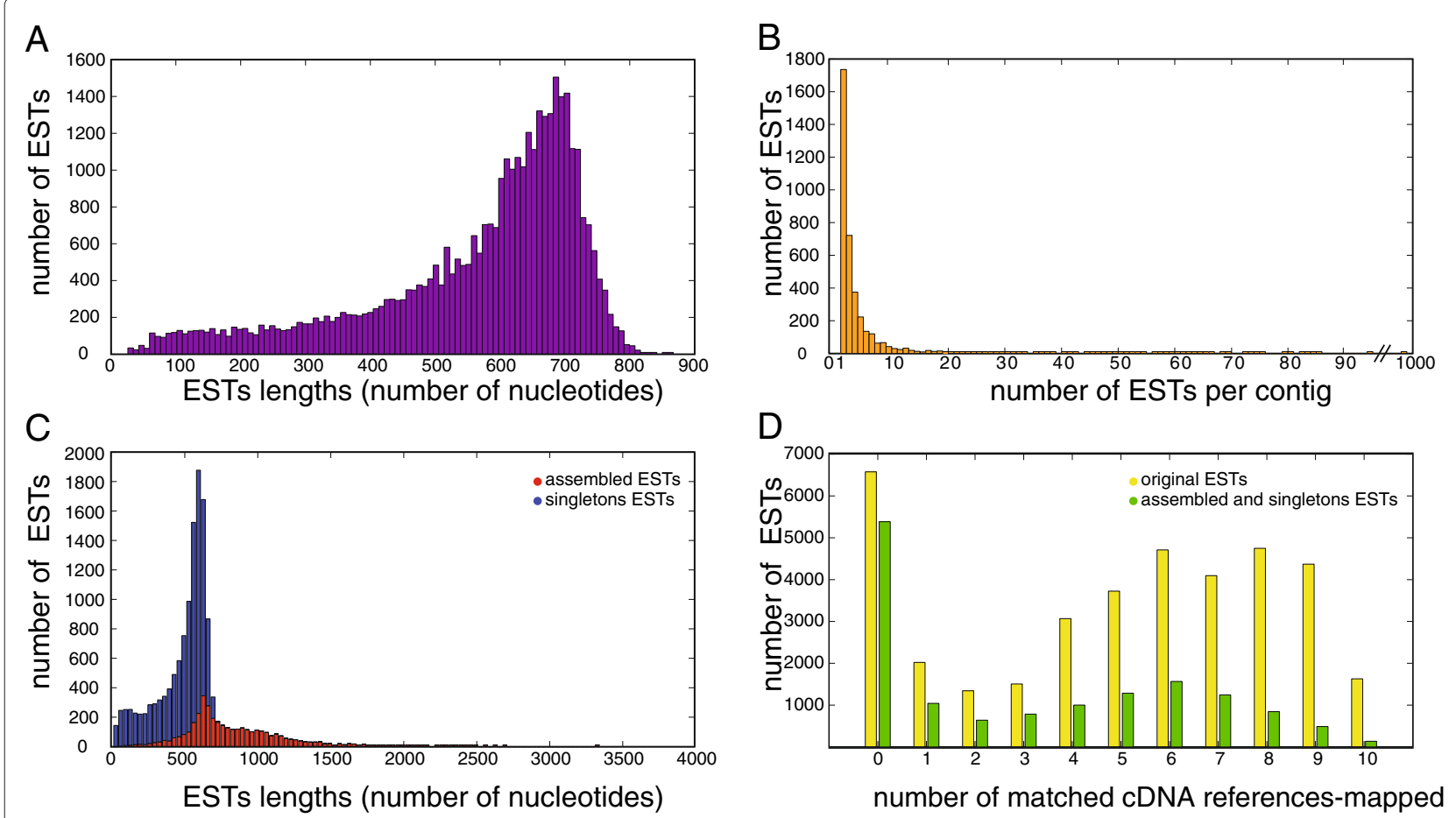

Figure 1 Composition and alignment distribution of the EST library and the assembled distinct transcripts. (A) Distribution of the length of the 37,787 original ESTs. The median EST length is equal to 618 nucleotides, the mean EST length is 563 nucleotides, and the standard deviation of the distribution is 167 nucleotides. (B) Distribution of the number of ESTs per contig in the ESTs assembly. The median number of ESTs per contig is equal to 3 ESTs, the mean number of ESTs per contig is 7 ESTs, and the standard deviation of the distribution is 27 ESTs. (C) Distribution of the length of the 14,410 distinct transcripts. The median sequence length is equal to 847 nucleotides, the mean sequence length is 943 nucleotides, and the standard deviation of the distribution is 388 nucleotides. The contribution of the assembled ESTs is shown in red while the contribution of singleton ESTs is shown in blue. (D) Distribution of the number of matched cDNA reference-mapped for both the 37,787 original ESTs (shown in yellow) and the 14,410 distinct transcripts (shown in green).

least one species. 29,191 of the total ESTs and 7,985 of the assembled ESTs have been aligned on at least two cDNA references. 1,628 of the total ESTs and 135 of the assembled ESTs have been aligned on all the 10 species, while 6,576 of the total ESTs and 5,384 of the assembled ESTs could not be mapped to any cDNA reference sets and are then potentially specific to the $C$. sabaeus transcriptome or highly diverse orthologs (Figure 1D). ESTs of the total and assembled AGM libraries have also been aligned to the draft assembly of the $M$. fascicularis genome [5] and a sequencing read library of the $C$. sabaeus genome [39]. Alignment results have been filtered to only keep for each EST the 5 best mapped reads when possible of the C. sabaeus draft scaffold genome, and the best mapped genomic position on the $M$. fascicularis draft assembly genome. Table 2 provides a summary of the results of the alignments with the $10 \mathrm{cDNA}$ references and the $2 \mathrm{draft}$ genomes. The highest number of aligned ESTs for both the original and the assembled ESTs was found for the H. sapiens $(\sim 80 \%$ of the original ESTs and $\sim 60 \%$ of the distinct transcripts) probably due to the relatively higher degree of investigation of this genome. The higher frequence as to compared to the ones of NHP is thus due to the broader sequence information from human genomes and does not reflect the biological dis-

Table 1 Composition details of the CDNA references

\begin{tabular}{lccc}
\hline $\begin{array}{l}\text { Species } \\
\text { name }\end{array}$ & $\begin{array}{c}\text { Release } \\
\text { version }\end{array}$ & $\begin{array}{c}\text { Number of } \\
\text { transcripts }\end{array}$ & $\begin{array}{c}\text { Number of } \\
\text { genes }\end{array}$ \\
\hline C. jacchus & Cjacchus3.2.1.63 & 55,137 & 32,339 \\
G. gorilla & gorGor3.63 & 35,727 & 29,216 \\
H. sapiens & GRCh37.63 & 174,598 & 53,894 \\
M. mulatta & MMUL_1.63 & 44,725 & 30,247 \\
M. murinus & micMur1.63 & 25,035 & 25,036 \\
N. leucogeny & Nleu1.0.63 & 31,550 & 26,526 \\
O. garnettii & BUSHBABY1.63 & 22,804 & 22,800 \\
P. troglodytes & CHIMP2.1.63 & 41,488 & 27,116 \\
P. abelii & PPYG2.63 & 31,566 & 28,088 \\
T. syrichta & tarSyr1.63 & 20,261 & 20,215 \\
\hline
\end{tabular}

For each species, the release version of the cDNA reference used and the number of transcripts and genes that composed the CDNA reference are indicated. All the cDNA references have been retrieved from the Ensembl [38] database. 
Table 2 Alignment results of ESTs on the different CDNA references and genomes

\begin{tabular}{|c|c|c|c|c|c|c|c|}
\hline \multirow[t]{2}{*}{ Species name } & \multirow[t]{2}{*}{ Target type } & \multicolumn{3}{|c|}{ Original ESTs } & \multicolumn{3}{|c|}{ Assembled and singleton ESTs } \\
\hline & & a.e. & m.t. & m.g. & a.e. & m.t. & m.g. \\
\hline C. jacchus & cDNA ref. & $24,461(64.73 \%)$ & 5,951 & 5,051 & $5,954(41.31 \%)$ & 4,928 & 4,504 \\
\hline G. gorilla & cDNA ref. & $23,633(62.54 \%)$ & 5,162 & 4,948 & $6,008(41.69 \%)$ & 4,622 & 4,527 \\
\hline H. sapiens & cDNA ref. & $30,117(79.70 \%)$ & 9,208 & 6,529 & $8,708(60.43 \%)$ & 7,316 & 6,128 \\
\hline M. mulatta & cDNA ref. & $24,213(64.07 \%)$ & 5,439 & 4,763 & $5,657(39,25 \%)$ & 4,585 & 4,273 \\
\hline M. murinus & cDNA ref. & $8,618(22.80 \%)$ & 1,770 & 1,770 & $1,240(08.60 \%)$ & 1,138 & 1,138 \\
\hline N. leucogeny & cDNA ref. & $22,600(59.80 \%)$ & 4,949 & 4,749 & $5,672(39.36 \%)$ & 4,389 & 4,296 \\
\hline O. garnettii & cDNA ref. & $7,564(20.01 \%)$ & 1,431 & 1,431 & 930 (06.45\%) & 861 & 861 \\
\hline P. troglodytes & cDNA ref. & 25,196 (66.67\%) & 5,699 & 5,156 & 6,332 (43.94\%) & 5,012 & 4,756 \\
\hline P. abelii & cDNA ref. & $18,904(50.02 \%)$ & 4,149 & 3,989 & 4,274 (29.65\%) & 3,415 & 3,340 \\
\hline T. syrichta & cDNA ref. & 5,327 (14.09\%) & 1,348 & 1,346 & 908 (06.30\%) & 854 & 854 \\
\hline C. sabaeus & d. scaf. & 37,409 (98.99\%) & - & - & $14,139(98,11 \%)$ & - & - \\
\hline M. fascicularis & d. assem. & $35,686(94,44 \%)$ & - & - & 13,392 (92.93\%) & - & - \\
\hline
\end{tabular}

For both the 37,787 originals ESTs and the 14,410 distinct transcripts, the number of aligned ESTs (a.e.) on the cDNA references (cDNA ref.), draft scaffold genome (d. scaf.), and draft assembly genome (d. assem.) are indicated. The number of mapped transcripts (m.t.) and mapped genes (m.g.) are also indicated for the cDNA references.

tances between the species. The C. jacchus, G. gorilla, $M$. mulatta, $N$. leucogeny, P. troglodytes species had relatively high-proportions of aligned ESTs ( $63 \%$ of the original ESTs and $\sim 41 \%$ of the distinct transcripts), and the $M$. murinus, O. garnettii, T. syrichta species had equally lowproportions of aligned ESTs ( $\sim 18 \%$ of the original library and $\sim 7 \%$ of the distinct transcripts). The $P$. abelii species had an intermediate proportion of aligned ESTs ( 50\% of the library and $\sim 30 \%$ of the distinct transcripts). We then performed Venn Diagrams between AGM and cDNA of the NHP species showing the highest proportions of aligned ESTs (M. mulatta, N. leucogeny, P. troglodytes, and H. sapiens), 31,005 of the 37,787 original ESTs and 8,909 of the 14,410 distinct transcrips could been aligned on at least one of the cDNA references (Figures $2 \mathrm{~A}$ and $2 \mathrm{~B}$ ). 23,450 of the original ESTs $(62.05 \%)$ were shared between the $H$. sapiens and M. mulatta species. AGM shared 25,196 sequences $(66.67 \%)$ with those of $M$. mulatta, and 17,743 (46.95\%) with the four species. The number of mapped ESTs on the C. sabaeus and M. fascicularis draft genomes is highly significant for both the original ESTs and the assembled and singletons ESTs, and almost the totality of the ESTs are commonly mapped ESTs between the two genomes (Figures $2 \mathrm{~A}$ and $2 \mathrm{~B}$ ). Note that the alignment to the draft genomes was performed using low-specificity alignment parameters
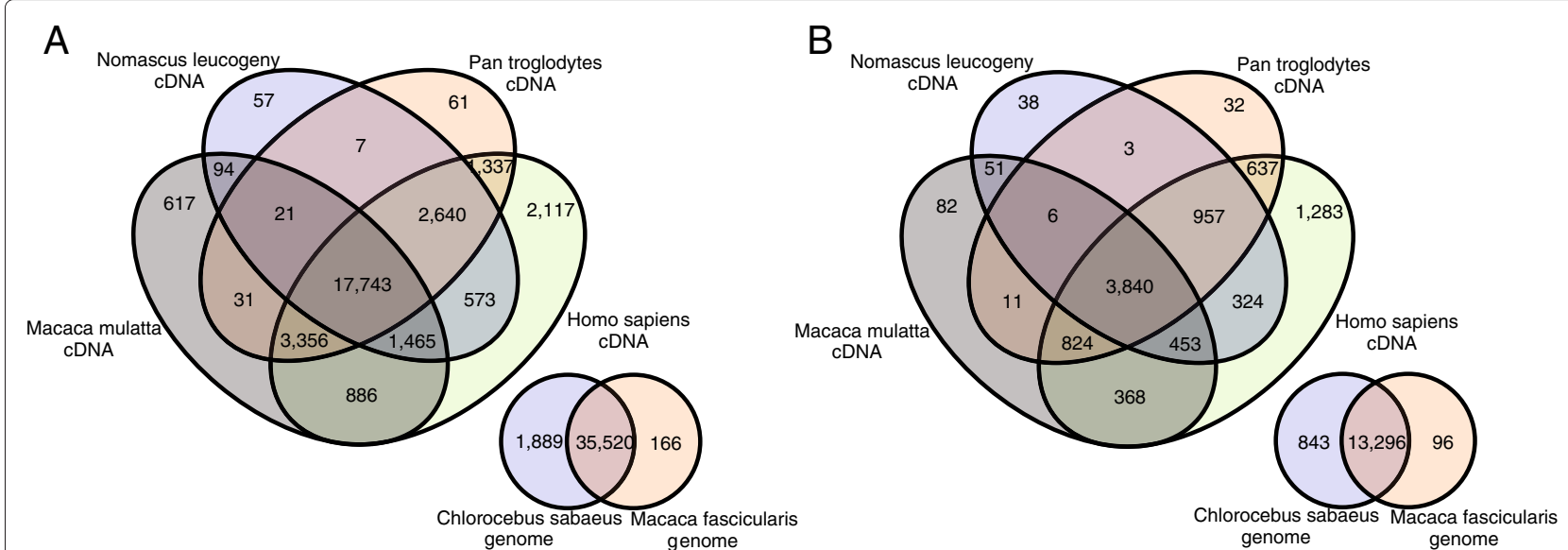

Figure 2 Inter- and intra- species alignment comparisons. (A) 4-set Venn diagram showing the intersections among the 4 sets of original ESTs aligned on the H. sapiens, M. mulatta, P. troglodytes, and P. abelii species, and 2-set Venn diagram showing the intersections between the 2 sets of original ESTs aligned over the C. sabaeus and M. fascicularis species. (B) Idem as A for the distinct transcripts. 
and thus is not directly comparable to the alignments of the EST libraries. Overall, while giving different specific alignment information, the number of mapped transcripts and mapped genes for both the 37,787 originals ESTs and the 14,410 distinct transcripts are convergent in the number of mapped genes and proportional with the genomic distances that exist among these species.

\section{Specific comparison with the Macaca mulatta transcriptome}

The M. mulatta species is the closest primate species to the $C$. sabaeus for which significant genomic information is available. In order to gain additional information about the transcript fragments that we provide, we annotated them with the particular section positions of the messenger RNAs available for the $M$. mulatta species. We specified for each EST of the assembled library the positions of the $5^{\prime}$-untranslated region (5'UTR), coding DNA sequence (CDS), and 3'-untranslated region (3'UTR) based on the $M$. mulatta cDNA reference annotations. Among the 14,410 assembled ESTs, 11,211 could be annotated: 6,244 ESTs with the 5'UTR, 9,657 ESTs with the CDS, and 5,313 ESTs with the 3'UTR. We report $506 \mathrm{M}$. mulatta transcripts that have been mapped to more than $90 \%$ by an EST (Additional file 2: Table S1). CXCL10 (Figure 3) and S100A4 (Additional file 3: Figure S2) are part of these transcripts and given as examples.

\section{Quantification of expressed sequences and functional pathway analysis of the EST library}

In order to have a quantitative view of the expressed sequences of the C. sabaeus PBMC, we identified the most expressed transcripts in our EST library based on the $M$. mulatta homolog transcripts. Based on the 44,725 transcripts of the $M$. mulatta cDNA reference and the 14,410 ESTs of the original ESTs library, we calculated for each transcript the number of sequences mapped and obtained a list of the 50 most expressed $M$. mulatta ortholog transcripts in our EST library (Table 3). Among these most expressed transcripts, the hemoglobin beta $(\mathrm{HBB})$ and alpha (HBA) genes were present, which might reflect a red blood cells contaminations of the PBMC, as well as more specific immune-related genes, such as CD74 and Granzyme B (GZMB). Some EST which correspond to genes which play an important role in immune responses against pathogens have been aligned: IRF7 (Figure 4), CD4 (Additional file 4: Figure S3), IFNG (Additional file 5: Figure S4), IFNGR1 (Additional file 6: Figure S5), IFNGR2 (Additional file 7: Figure S6). For all these transcripts, EST alignment positions as well as protein domains are given. Furthermore, in order to identify the over-represented pathways in our AGM EST library, we performed a functional canonical pathway analysis based on the list of the 9,208 $H$. sapiens transcripts uniquely mapped by the 37,787 original ESTs. Most of the canonical pathways found as statistically significantly over-represented are related to $B$ and $T$ cell signaling, and immune response pathways (Table 4). For instance, the "CD28 signaling in $\mathrm{T}$ Helper Cells", "iCOS-iCOSL signaling in T Helper Cells", "B Cell receptor Signaling" (Additional file 8: Figure S7A), and "T Cell receptor signaling" (Additional file 8: Figure S7B) pathways belong to the list of pathways found as significantly over-represented in our AGM library, as well as the "Glucocorticoid receptor signaling", "Role of NFAT in regulation of the immune response" (Additional file 9: Figure S8A), "Antigen presentation pathway" (Additional file 9: Figure S8B), "JAK/STAT signaling", and many different "Interleukin signaling" pathways. As a result of the in vitro stimulation of SIV-infected PBMC, the "NF- $\kappa \mathrm{B}$ Activation by viruses" (Additional file 10: Figure S9A) and "Induction of apoptosis by HIV-1" (Additional file 10: Figure S9B) pathways are also significantly overrepresented. Consistent with the stimulation by LPS, the "Interferon Signaling" (Figure 5A) and "Toll-like Receptor Signaling" (Figure 5B) pathways are also found significantly over-represented. Finally, ConA is capable of triggering positive selection in mature $\mathrm{T}$ cells by crosslinking the TCR with high avidity $[40,41]$ and we found 8 pathways corresponding to these functions being induced (Table 4). The over-representation of gene transcripts belonging to these pathways of the immune system further indicates that this library is a valuable resource for profiling global gene expression in AGM immune cells. Overall, these gene and pathway information are consistent with what we could expect from an EST PBMC library.

\section{Analysis of the inter-species genomic relationships}

Analysis of genomic relationships among species is an important way for studying evolution of genomic features. The relationships of the C. sabaeus EST with the 10 above described primate species for which the cDNA references were available have been quantified. For each one of the 1,628 ESTs aligned on all the cDNA references, multiple sequence alignment scores have been computed. Based on these pairwise alignment scores, an average genomic distance matrix has been computed (Table 5) and a phylogenetic tree constructed (Figure 6A). As it would be expected, the $H$. sapiens and $P$. troglodytes are clustered together, as it is also the case for the C. sabaeus and $M$. mulatta. The G. gorilla, P. abelii, and N. leucogeny were located between these two clusters, and the C. jacchus, M. murinus, O. garnettii, and T. syrichta are segregated from other species. By comparing only to the more related species, phylogenetic trees have also been computed with a higher number of AGM ESTs with all the 14,410 assembled transcripts (Figure 6B). Finally, trees have been 
CXCL10

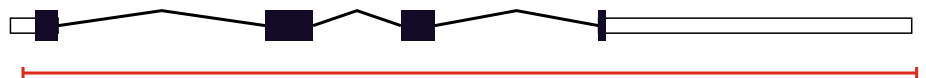

(1)

(1)

1 TTCCTCAACTGCTTAGACATATTCTGAGCCCGCAGCAGAGGAATCTCCAGTCTCAGCACCATGAATCAAACTACCATTCTGATTTGCTGCCTTGTCTTTC 100 1 TTCCTCAACTGCT AAGACATAT TCTGAGCCCGCAGCAGAGGAATCTCCAGTCTCAGCACCATGAATCAAACTACCATTCTGATTTGCTGCCTTGTCTTTC 100
1 TTCCTCAACTGCTTAGACATATTCTGAGCCTGCAGCAGAGGATCTCCAGTCTCAGCACCATGAATCAACTACCATTCTGATTGCTGCCTTGTCTTTC 100

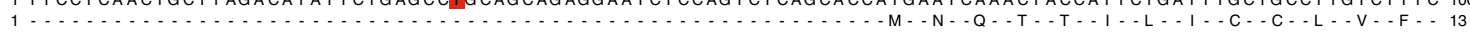

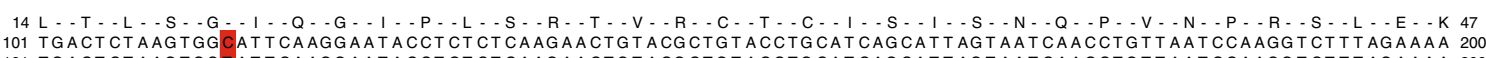
101 TGACTCTAAGTGGTATTCAAGGAATACCTCTCTCAAGAACTGTACGCTGTACCTGCATCAGCATTAGTAATCAACCTGTTAATCCAAGGTCTTTAGAAAA 200

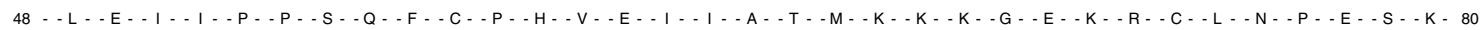
201 ACTTGAATTATTCCTCCAAGTCAATTTTGTCCACATGTTGAGATCATTGCTACAATGAAAAAGAGGGTGAGAGAGGTTCTGAATCCAGAATCTAAG 300 201 ACTTGAAATATTCCTCCAAGTCAATTTGTCCACATGTTGAGATCATTGCTACAATGAAAAAGAGGGTGAGAGAGGGTCTGAATCCAGAATCTAAG 300

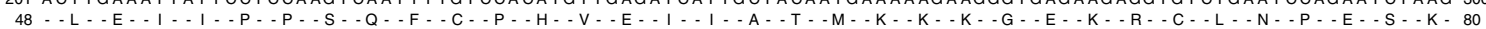

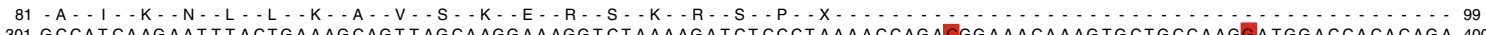
301 GCCATCAAGAATTTACTGAAAGCAGTTAGCAAGGAAAGGTCTAAAAGATCTCCCTAAAACCAGACGGAAACAAAGTGCTGCCAAGGATGGACCACACAGA 400

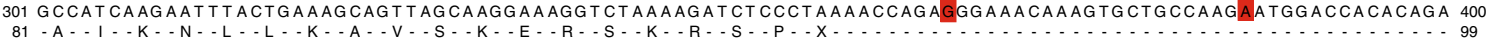
GTTCTAGTTTGCAGTTCCA 401 GGCTGCCTCTCCCATCACTTCCCTACATGGAGTATATGTCAAGCCCTAATTGTTCTTAGTTTGCAGTTCCA

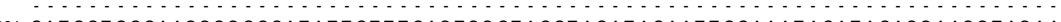
(1) 800 CATCCTCCCAAGGGGCCCATATTCTTTCAGTGGCTACCTACATACAATT CCAAATACATACAGGAAGGTAGAAACATCTGAAATGTAT.-GTAATAT 897 901 CTTATTTAATGAAAGACTGTACAAAGTAGAAGTCTTAGATGTATATATTTCCTATATTGTTTTCAGTGTACATGGAATAACTTATGTAATTATGTACTAT 1000 898 CT TATT TAATGAAAGACTGTACAAAGTAGAAGT TT AGATGTATATATTTCCTATATTGTTTTCAGTGTACATGGAATAACTTATGTAATTATGTACTAT 997

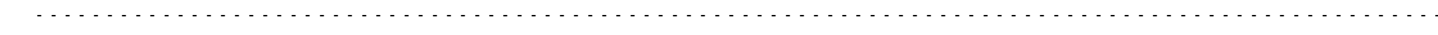

constructed for specific sections of the transcripts: 5'UTR regions (Figure 6C), CDS sections (Figure 6D), and 3'UTR regions (Figure 6E). Both the phylogenetic trees restricted on the CDS and 3'UTR sections show a clusterisation of the $C$. sabaeus with the M. mulatta and a strong segregation with other species. Interestingly, the phylogenetic tree restricted on the 5'UTR sections revealed a different shape. C. sabaeus and the $N$. leucogeny species clustered together, suggesting distinct selective pressures in the 5’UTR as compared to other regions.

\section{Discussion}

AGMs have provided useful animal models in biomedical research for many years [17,42-50]. They are also becoming a more and more essential model to the study of human biology and disease, such as neurological disorders $[51,52]$ and AIDS $[19,53]$. Several studies could not be conducted so far because of the insufficiency of genomic resources on this primate [7]. This is a major limitation in view of the information that new generation technologies can offer for the progress in development of strategies to 
Table 3 List of the 50 most expressed $M$. mulatta ortholog transcripts in present EST library

\begin{tabular}{|c|c|c|c|}
\hline Transcript ID & Gene symbol & Gene description & Count \\
\hline ENSMMUT00000006876 & HBB_MACMU & Hemoglobin subunit beta & 941 \\
\hline ENSMMUT00000045385 & LOC712934 & & 699 \\
\hline ENSMMUT00000012750 & CD74 & & 526 \\
\hline ENSMMUT00000015401 & Q3YAP9_MACMU & eukaryotic translation elongation factor 1 alpha 1 & 519 \\
\hline ENSMMUT00000000859 & $\mathrm{HBA} \perp \mathrm{MACMU}$ & Hemoglobin subunit alpha & 296 \\
\hline ENSMMUT00000017004 & LOC712553 & & 257 \\
\hline ENSMMUT00000038286 & & MTRNR2-like (LOC100499503) & 232 \\
\hline ENSMMUT00000005322 & B2MG_MACMU & Beta-2-microglobulin & 212 \\
\hline ENSMMUT00000005104 & LOC708526 & & 208 \\
\hline ENSMMUT00000043999 & RPL3 & ribosomal protein $\mathrm{L} 3$ & 208 \\
\hline ENSMMUT00000038271 & COX2_MACMU & Cytochrome c oxidase subunit 2 & 194 \\
\hline ENSMMUT00000027050 & DRA_MACMU & Mamu class II histocompatibility antigen, DR alpha chain & 191 \\
\hline ENSMMUT00000038268 & Q6IYH3_MACMU & ATP synthase F0 subunit 6 & 185 \\
\hline ENSMMUT00000029930 & Q3YAP9」MACMU & eukaryotic translation elongation factor 1 alpha 1 & 173 \\
\hline ENSMMUT00000045510 & Q9GMG8」MACMU & acidic ribosomal phosphoprotein PO & 173 \\
\hline ENSMMUT00000023666 & LOC710590 & & 155 \\
\hline ENSMMUT00000039116 & LOC714576 & & 144 \\
\hline ENSMMUT00000027943 & B0Z9V5_MACMU & major histocompatibility complex, class I, E & 143 \\
\hline ENSMMUT00000038267 & Q6IYH2_MACMU & cytochrome c oxidase subunit III & 135 \\
\hline ENSMMUT00000010560 & B5MBT6」MACMU & ribosomal protein L13a & 133 \\
\hline ENSMMUT00000032800 & UBB & polyubiquitin-B & 133 \\
\hline ENSMMUT00000010558 & Q3YAQ2_MACMU & ribosomal protein S11 & 131 \\
\hline ENSMMUTO0000011109 & & ribosomal protein S2 (RPS2) & 131 \\
\hline ENSMMUT00000015005 & LOC711043 & & 129 \\
\hline ENSMMUT00000020179 & GZMB & & 126 \\
\hline ENSMMUT00000033466 & Q6IEB8_MACMU & interferon alpha-inducible protein 27 & 123 \\
\hline ENSMMUT00000038664 & LOC719242 & & 123 \\
\hline ENSMMUT00000008204 & Q6IUG4_MACMU & glyceraldehyde-3-phosphate dehydrogenase & 122 \\
\hline ENSMMUT00000029999 & RPS20 & & 116 \\
\hline ENSMMUT00000032342 & TPT1 & & 116 \\
\hline ENSMMUT00000012806 & Q9GMG8」MACMU & acidic ribosomal phosphoprotein PO & 115 \\
\hline ENSMMUT00000005819 & SRGN & & 107 \\
\hline ENSMMUT00000040341 & Q9MXS5_MACMU & MHC class I antigen & 106 \\
\hline ENSMMUT00000014609 & LOC711421 & & 105 \\
\hline ENSMMUT00000004034 & LOC710901 & & 104 \\
\hline ENSMMUT00000009232 & EEF1G & eukaryotic translation elongation factor 1 gamma & 103 \\
\hline ENSMMUT00000027208 & A2TJ58」MACMU & major histocompatibility complex, class II, DP alpha & 94 \\
\hline ENSMMUT00000013155 & Q6RHR8_MACMU & actin, cytoplasmic 1 & 93 \\
\hline ENSMMUT00000041082 & EOWHM2_MACMU & MHC class I antigen & 92 \\
\hline ENSMMUT00000043841 & RPS3 & & 89 \\
\hline ENSMMUT00000022628 & A8QWZ5_MACMU & MHC class I antigen & 86 \\
\hline ENSMMUT00000000617 & RPL12 & 605 ribosomal protein L12 & 85 \\
\hline ENSMMUT00000018897 & RPS6 & & 84 \\
\hline ENSMMUT00000025324 & ARHGDIB & & 79 \\
\hline
\end{tabular}


Table 3 List of the 50 most expressed M. mulatta ortholog transcripts in present EST library (Continued)

\begin{tabular}{llll}
\hline ENSMMUT00000011502 & A3F8W8_MACMU & MHC class II antigen & 77 \\
ENSMMUT00000040916 & A3F8W8_MACMU & MHC class II antigen & 76 \\
ENSMMUT00000005540 & LOC718964 & \\
ENSMMUT00000018430 & & & 75 \\
ENSMMUT00000041189 & A9XN15_MACMU & major histocompatibility complex, class I, A & 75 \\
ENSMMUT00000015586 & Q6UIS1_MACMU & Actin beta subunit & 73
\end{tabular}

For each of the 44,725 transcripts of the M. mulatta cDNA reference, we calculated the number of original ESTs mapped, and obtained a list of the 50 most expressed M. mulatta ortholog transcripts in our EST library. For each of the most expressed M. mulatta ortholog transcript, the Ensembl transcript ID, the gene symbol, the gene description, and the number of mapped ESTs is given.

prevent or treat human diseases. The growing interest for this model is shown through the increase of the number of sequences published in the NCBI nucleotide database for this species every year (Additional file 1: Figure S1) and the sequencing of its genome which is underway. Nevertheless, our recent survey (as of January 11, 2012) showed that while there were $11,413,043$ and 225,854 nucleotide sequences available for $H$. sapiens and $M$. mulatta, respectively, there were still only 2,527 nucleotide sequences for AGM in the databases. The primary goal of this study was to enhance the development of an AGM genomic resource through the construction, sequencing and characterization of a PBMC cDNA library of AGM (C. sabaeus). The results could be used to expand genomic research activities on this species.

We focused here on the construction of a cDNA library on blood immune cells (PBMC) in order to get as much immune defense genes as possible which could help to the study of several disease mechanisms such as the understanding of AIDS resistance in AGM. Therefore, to increase the expression of such genes, the cells were challenged or not with immune-relevant stimuli (ConA, LPS, MLR). We also chose to work on both, SIV-infected and non-infected animals, in order to eventually reveal new genes that might have a unique role in AIDS resistance in this natural host. The sequencing of the cDNAs yielded 37,787 ESTs with 14,410 assembled and singletons ESTs which cover $12 \%$ of the transcriptome. For annotation purpose, we aligned the 14,410 cDNA sequences of our library to the known cDNA libraries of 10 other primate species including the human one. Of the 31,005 ESTs identified, as many as 6,576 ESTs did not match any gene reported in the database. This high number of novel sequences might be due to the fact that the genomes of the other NHP species are not sufficiently annotated yet. However, a few of them might be true new gene candidates. Indeed, the stimulation used might have revealed a number of silent genes only expressed under the condition of infection.

As one would expect, at the CDS level, the divergence between $C$. sabaeus and M. mulatta was lower than between $C$. sabaeus and the other primate species. The gene distance at the non-coding regions was higher than in the CDS and higher for 5'UTR than 3'UTR. Interestingly, the 5'UTR of C. sabaeus did not cluster any more with $M$. mulatta, at least not consistently. This is in line with the fact that on average, 5' and 3' UTRs are less conserved across species than protein-coding sequences, with the 5'UTR being the most divergent, but still more conserved than untranscribed sequences $[54,55]$. It has been shown that high differences in the 5'UTR of orthologous genes correlate with their expression levels [56]. Indeed, this region is rich in regulatory elements. Changes in the regulation of gene expression levels play an important role in phenotypic diversity among closely related organisms $[57,58]$. The high distances observed at the 5'UTR region between the different primate species studied here might reflect part of these changes (Additional file 11: Table S2). However, we can not exclude that on one hand, our analyses might have misestimated the gene distance of UTR or ESTs in general, between the C. sabaeus and other species, as the length of the ESTs of our library are shorter (943 nucleotides) than the average length of human and macaque cDNAs (1,500 nucleotides) in the databases. On the other hand we might have overestimated this distance as compared to the rest of the transcriptome because the genes included in this library are mostly immune-related, thus among the most known divergent genes [59].

To further analyze the library, we determined the biological pathways represented by the 14,410 annotated ESTs. Among more general pathways (protein ubiquitination pathway, mitochondrial pathway), many pathways were related to the immune system ( $\mathrm{T}$ cell activation, $B$ cell activation) indicating the immune-specificity of the starting cells. The immune pathways appear well conserved in AGM, with most of the key components found in our library under the stimulation condition used (Figure 5 and Additional file 8: Figures S7, Additional file 9: Figures S8 and Additional file 10: Figures S9). Ubiquitously expressed genes, such as ribosomal proteins, housekeeping genes and mitochondrial pathway, are also included in this library and could be useful when 


\section{IRF7}

\section{(1)}

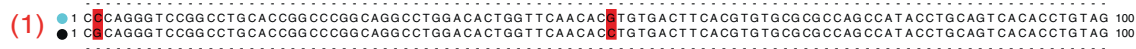

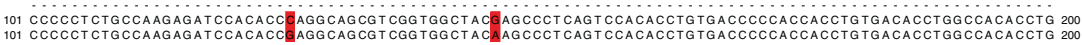

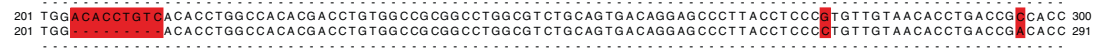

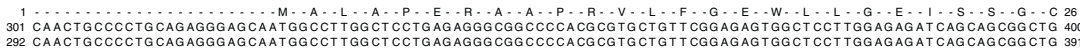

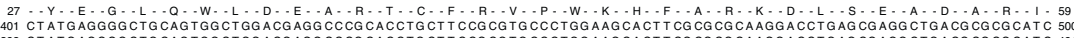

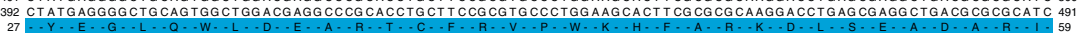

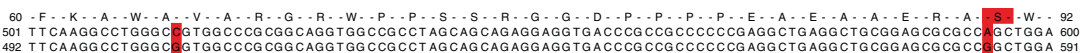

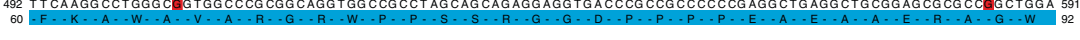

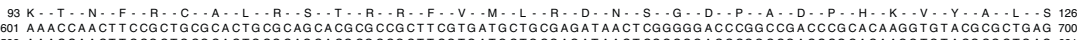

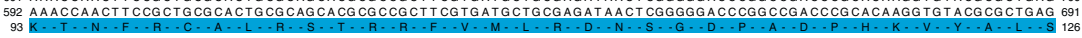

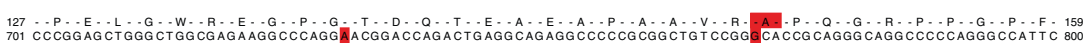

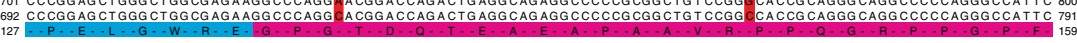

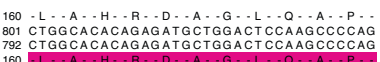

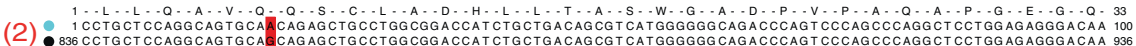

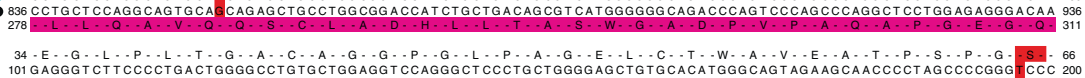

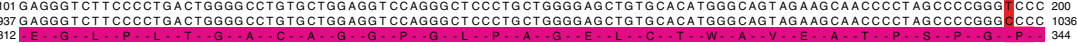

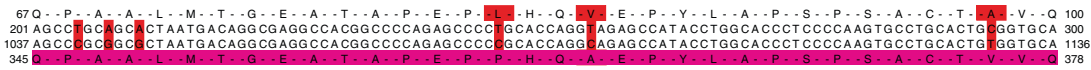

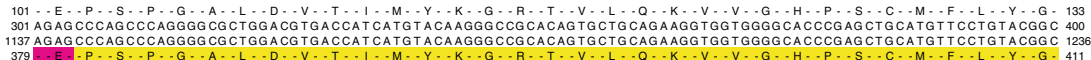

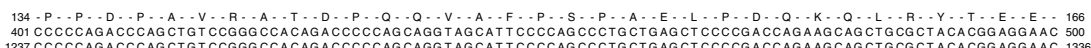

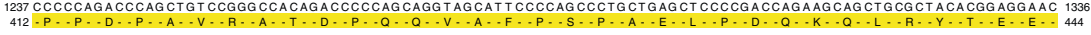

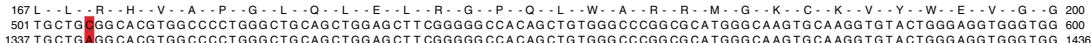

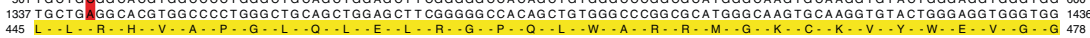

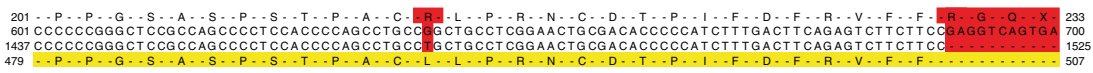

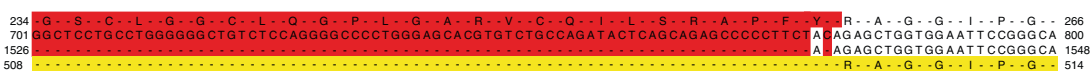

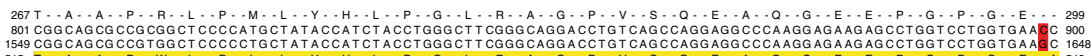

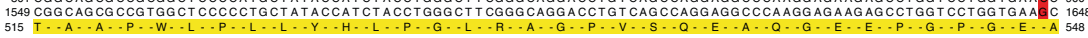

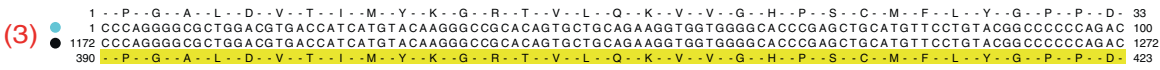

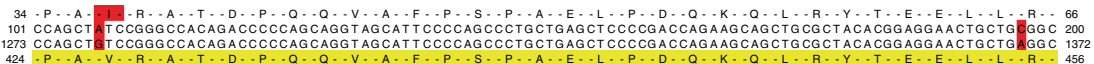

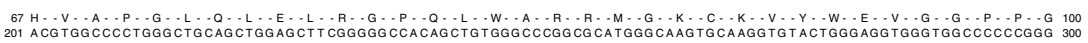

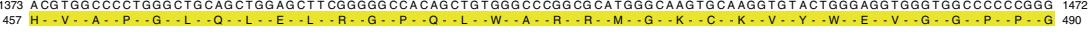

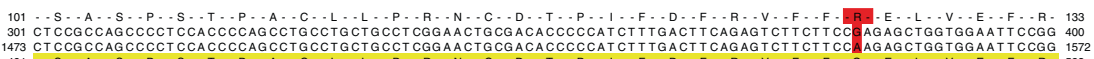

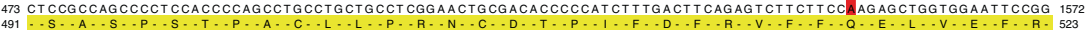

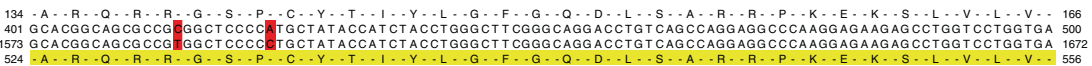

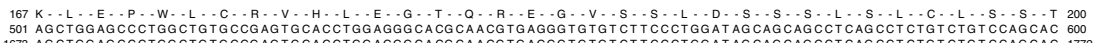

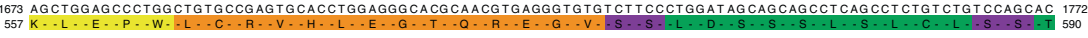

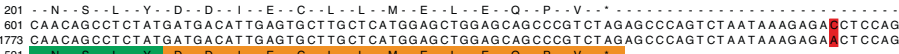

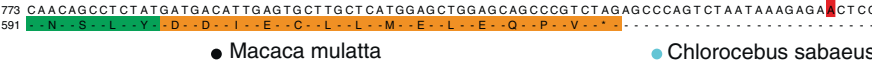

\begin{tabular}{|c|c|c|c|}
\hline dip & Transactivation & Autoinhibitory & Phosphorylation \\
\hline
\end{tabular}

Figure 4 Alignment details for the the IRF7 gene. Alignment details for the Interferon regulatory factor 7 gene of the M. mulatta species (Ensembl ID: ENSMMUT00000009923). Assembled ESTs have been aligned at different positions of the gene: (1) Contig3553, (2) Contig866, (3) Contig1898. Same legend and nomenclature as in Figure 3. 
Table 4 Top 50 canonical pathways found as significantly over-represented in present EST library

\begin{tabular}{|c|c|c|}
\hline Canonical pathway & $-\log (q$-value $)$ & gen $_{a} /$ gen $_{b}$ \\
\hline Protein Ubiquitination Pathway & 16.80 & $148 / 274(54 \%)$ \\
\hline Glucocorticoid Receptor Signaling & 16.80 & 148/295 (50\%) \\
\hline Oxidative Phosphorylation & 15.00 & $92 / 159(58 \%)$ \\
\hline Mitochondrial Dysfunction & 14.00 & $86 / 175(49 \%)$ \\
\hline CD28 Signaling in T Helper Cells & 13.70 & $77 / 132(58 \%)$ \\
\hline Regulation of elF4 and p70S6K Signaling & 11.90 & $69 / 132(52 \%)$ \\
\hline Role of NFAT in Regulation of the Immune Response & 10.70 & $97 / 200(49 \%)$ \\
\hline EIF2 Signaling & 10.60 & $57 / 101(56 \%)$ \\
\hline PI3K/AKT Signaling & 10.50 & $73 / 140(52 \%)$ \\
\hline iCOS-iCOSL Signaling in T Helper Cells & 10.50 & $67 / 122(55 \%)$ \\
\hline B Cell Receptor Signaling & 10.10 & $83 / 156(53 \%)$ \\
\hline Regulation of IL-2 Expression in Lymphocytes & 9.70 & $53 / 89(60 \%)$ \\
\hline Integrin Signaling & 9.48 & $104 / 209(50 \%)$ \\
\hline PKC $\theta$ Signaling in T Lymphocytes & 8.93 & $68 / 142(48 \%)$ \\
\hline Hypoxia Signaling in the Cardiovascular System & 8.93 & $46 / 68(68 \%)$ \\
\hline CTLA4 Signaling in Cytotoxic T Lymphocytes & 8.52 & $57 / 98(58 \%)$ \\
\hline mTOR Signaling & 8.51 & $79 / 162(49 \%)$ \\
\hline T Cell Receptor Signaling & 8.43 & $59 / 109(54 \%)$ \\
\hline Type I Diabetes Mellitus Signaling & 8.32 & $64 / 121(53 \%)$ \\
\hline Production of Nitric Oxide and ROS in Macrophages & 8.32 & $83 / 187(44 \%)$ \\
\hline Ubiquinone Biosynthesis & 8.05 & 45/112 (40\%) \\
\hline Molecular Mechanisms of Cancer & 7.64 & $152 / 377(40 \%)$ \\
\hline Estrogen Receptor Signaling & 7.54 & $70 / 136(51 \%)$ \\
\hline Antigen Presentation Pathway & 7.20 & $30 / 43(70 \%)$ \\
\hline Apoptosis Signaling & 7.19 & $53 / 96(55 \%)$ \\
\hline G2/M DNA Damage Checkpoint Regulation & 7.19 & $32 / 49(65 \%)$ \\
\hline Prostate Cancer Signaling & 6.96 & $49 / 97(51 \%)$ \\
\hline Phospholipase C Signaling & 6.79 & $109 / 260(42 \%)$ \\
\hline Huntington's Disease Signaling & 6.78 & $104 / 238(44 \%)$ \\
\hline Chronic Myeloid Leukemia Signaling & 6.65 & $54 / 105(51 \%)$ \\
\hline Pancreatic Adenocarcinoma Signaling & 6.61 & $59 / 119(50 \%)$ \\
\hline IL-8 Signaling & 6.60 & $86 / 193(45 \%)$ \\
\hline PI3K Signaling in B Lymphocytes & 6.50 & $69 / 143(48 \%)$ \\
\hline Breast Cancer Regulation by Stathmin 1 & 6.49 & $93 / 208(45 \%)$ \\
\hline IL-2 Signaling & 6.31 & $35 / 58(60 \%)$ \\
\hline NF- $\kappa$ B Activation by Viruses & 6.26 & $44 / 82(54 \%)$ \\
\hline IL-15 Signaling & 6.23 & $39 / 68(57 \%)$ \\
\hline THelper Cell Differentiation & 6.15 & $42 / 72(58 \%)$ \\
\hline TREM1 Signaling & 6.05 & $35 / 66(53 \%)$ \\
\hline Fc $\gamma$ Receptor-mediated Phagocytosis in Macrophages & 5.98 & $52 / 102(51 \%)$ \\
\hline Pyrimidine Metabolism & 5.85 & $70 / 213(33 \%)$ \\
\hline GM-CSF Signaling & 5.69 & $38 / 67(57 \%)$ \\
\hline Induction of Apoptosis by HIV1 & 5.64 & $37 / 66$ (56\%) \\
\hline
\end{tabular}




\begin{tabular}{lcc}
\hline Dendritic Cell Maturation & 5.64 & $78 / 188(41 \%)$ \\
NRF2-mediated Oxidative Stress Response & 5.63 & $86 / 193(45 \%)$ \\
Purine Metabolism & 5.56 & $117 / 391(30 \%)$ \\
fMLP Signaling in Neutrophils & 5.50 & $57 / 128(45 \%)$ \\
JAK/Stat Signaling & 5.42 & $37 / 64(58 \%)$ \\
HMGB1 Signaling & 5.40 & $51 / 100(51 \%)$ \\
IL-4 Signaling & 5.40 & $40 / 73(55 \%)$ \\
\hline
\end{tabular}

List of the top 50 canonical pathways found as statistically significantly over-represented in the functional pathway analysis of the EST library. For each canonical pathway, the associated multiple testing corrected p-value (shown as - log (q-value)) is indicated as well as the ratio between the number gen $n_{a}$ of genes of the pathway mapped by the EST library and the total number gen $b$ of genes defining the pathway.

using cell lines derived from AGM such as COS-7 and Vero cells. We studied in more detail genes which are of major importance for host immune defenses, such as IFN- $\gamma$, IFNGR, CXCL10 and IRF7 [60-62]. For the IFN- $\gamma$ receptor (IFNGR), it has been shown in humans that any variation having a significant impact on IFNGR function is not tolerated [63]. Therefore, the deletion observed in the cytoplasmic tail of IFNGR1 in AGM as compared to macaque might either not have any functional consequence on this pathway or give to this species a yet unknown evolutionary advantage. Thus, it would be interesting to compare the sequence of AGM IFNGR1 with other SIV natural hosts in order to evaluate if this might play a role in AIDS resistance. CXCL10 (or IP-10) is a chemokine involved in the recruitment of cells of the immune system to sites of inflammation and is induced by IFN- $\alpha$ and IFN- $\gamma$ [60]. Alteration of IP-10 expression has been associated with inflammatory diseases including infectious diseases, immune dysfunction and tumor development $[64,65]$. We did not find any difference at the amino acid level between the CXCL10 from C. sabaeus and the one from M. mulatta. This conservation suggests that any variation having an impact on CXCL10 function could be deleterious. IRF7 encodes a transcription factor which plays a role in the activation of virusinducible cellular genes, including the type I interferon genes. The partial sequences from our library did not show the same mutations that were suggested to play a role in AIDS-resistance in another SIV-natural host, the sooty mangabey [66]. The mutations in IRF7 reported in one SM [66], were however also either not confirmed when studied in a large number of SM animals or found to be non-fixed and with no effects on the phenotype even when present in homozygosity (Johnson Z, Silvestri G, and Bosinger SE, personal communication). However, as this is not the same species, the mutations could be at other sites, or the mechanisms of AIDS resistance might be different between AGM and sooty mangabey. As our library was constructed on a pool of cells from 16 different animals, the sequences obtained are not representative of the inter-individual variability and need to be verified on the individual level for further studies.

To our knowledge, this is the first time that abundant genetic information on AGM is given. In this study, a total of 37,787 ESTs were sequenced, from which 14,410 contigs and singletons were identified, covering $12 \%$ of the AGM transcriptome. Moreover, this cDNA library provides both a large collection of novel transcripts and a detailed annotation of immune genes. The high volume of apparently novel AGM sequences suggests that our data could be a useful resource for future genomic investigation.

\section{Methods}

\section{Construction and sequencing of the EST library}

Twelve SIV-infected and four non-infected C. sabaeus (from Caribbean islands) were used in this study. The Central Committee for Animals at Institut Pasteur, Paris, France, reviewed and approved the use and care of animals. The experiments were performed according to national and European guidelines. Whole blood was collected from monkeys under anesthesia in heparinized tubes. PBMC were isolated from whole blood by density gradient centrifugation using the Lymphocyte Separation Medium 1077 (PAA Laboratories $\mathrm{GmbH}$ ) and activated or not with different stimuli in RPMI- 1640 with $10 \%$ fetal calf serum. For ConA activation (from Canavalia ensiformis (Sigma-Aldrich, St. Louis, MO, USA)): $4.10^{6}$ of isolated PBMC were plated with $10 \mu g \cdot m l^{-1}$ of ConA for 2, 6, 24, 36 or $72 \mathrm{~h}$. For LPS (E.Coli 0111:B4 Sigma (L2630)) activation: $4.10^{6}$ of isolated PBMC were plated with $10 \mu g . m l^{-1}$ of LPS for 2, 6, 24, 36 or 72 hours. The MLR were done by mixing $4.10^{6}$ of isolated PBMC with $4.10^{5}$ PBMC from another animal for 2, 6, 24, 36 or 72h. Unstimulated cells were also kept for further RNA extraction. Total RNA was extracted from harvested cells by using the RNeasy ${ }^{\circ} \mathrm{Mini}$ Kit (Qiagen, Courtaboeuf, France) following the manufacturer's instructions. Briefly, cells were lysed in $350 \mu \mathrm{l}$ of RLT buffer, run over a QiaShredder column (Qiagen) to ensure homogeneous lysis, and resuspended in $30 \mu \mathrm{l}$ 


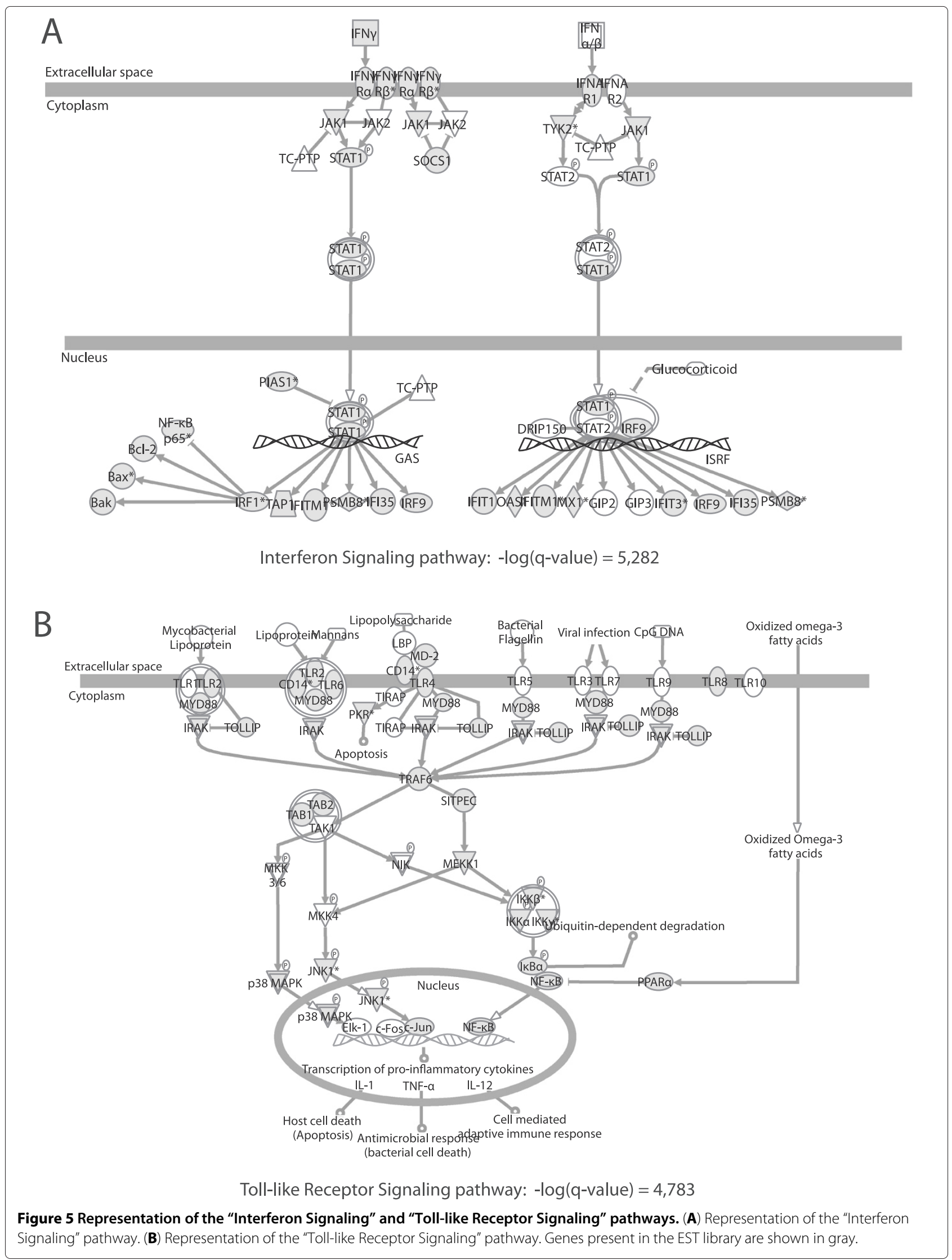


Table 5 Pairwise genomic distance matrix of the 11 primate species

\begin{tabular}{|c|c|c|c|c|c|c|c|c|c|c|}
\hline & C. sabaeus & G. gorilla & H. sapiens & M. mulatta & M. murinus & N. leucogeny & O.garnettii & P. troglodytes & P. abelii & T. syrichto \\
\hline C. jacchus & 474 & 445 & 430 & 474 & 804 & 445 & 906 & 442 & 442 & 862 \\
\hline C. sabaeus & & 272 & 260 & 140 & 751 & 284 & 856 & 272 & 289 & 832 \\
\hline G. gorilla & & & 103 & 263 & 741 & 191 & 858 & 117 & 200 & 830 \\
\hline H. sapiens & & & & 248 & 712 & 173 & 835 & 78 & 176 & 808 \\
\hline M. mulatta & & & & & 754 & 266 & 873 & 259 & 290 & 842 \\
\hline M. murinus & & & & & & 753 & 770 & 734 & 743 & 897 \\
\hline N. leucogeny & & & & & & & 876 & 185 & 224 & 842 \\
\hline O. garnettii & & & & & & & & 850 & 880 & 1006 \\
\hline P. troglodytes & & & & & & & & & 191 & 824 \\
\hline P. abelii & & & & & & & & & & 859 \\
\hline
\end{tabular}

Pairwise genomic distance matrix computed using the ESTs of the original library and the CDNA references of the 10 primates species for which the cDNA references were available. For pairs of species, the average multiple alignment score calculated over the 1,628 commonly aligned sequences is given. Scores have been rescaled by multiplication by $10^{4}$. 


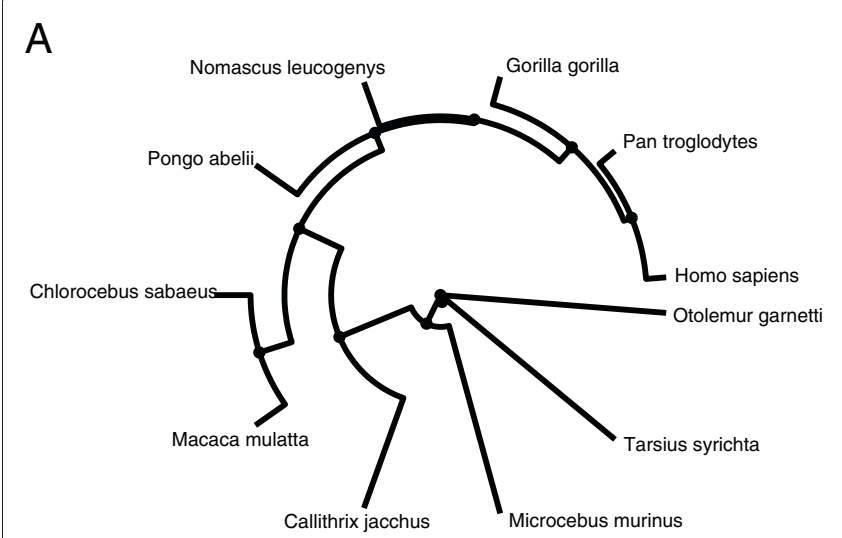

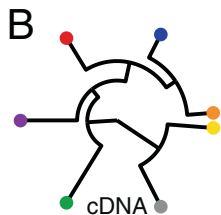
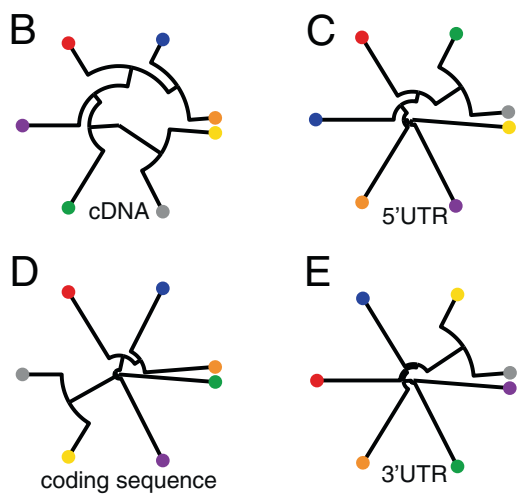

Chlorocebus sabaeus - Gorilla gorilla Homo sapiens Macaca mulatta Nomascus leucogeny - Pan troglodytes - Pongo abelii

Figure 6 Evolutionary relationships among primates species. (A) phylogenetic tree of the 11 primate species for which the cDNA references were available calculated based on the 1,628 common original ESTs. (B) phylogenetic tree of the old world monkeys and human species calculated based on the 8,788 common assembled ESTs. (C) phylogenetic tree of the old world monkeys and human restricted to the $5^{\prime} U T R$ of the transcripts calculated based on the 1,016 common assembled ESTs. (D) phylogenetic tree of the old world monkeys and human restricted to the coding sequence of the transcripts calculated based on the 8,024 common assembled ESTs. (E) phylogenetic tree of the old world monkeys and human restricted to the 3'UTR of the transcripts calculated based on the 2,209 common assembled ESTs.

of sterile water. We added a DNase-RNase free (Qiagen) treatment on the column to eliminate any potential DNA contamination of RNA preparations. The quality and concentration of RNA was assessed as before [36]. The libraries were plated, arrayed robotically and bacterial clones have their plasmid DNA amplified using phi29 polymerase. The plasmids were end-sequenced by the Genoscope using BigDye Termination kits on Applied Biosystems 3730xl DNA Analysers.

\section{EST quality filtering}

Poly-A and poly-T tails have been trimmed from the sequenced ESTs by using the trimest tool [67] (default parameters have been used) while starting and ending terminal N's have been trimmed from the sequences using the trimseq tool [67] (a threshold cutoff parameter of 20\% of Ns in a window of 30 nucleotides has been used).

\section{Assembly of the EST library}

Assembly of ESTs into contigs has been performed using the EGassembler [68] tool. EGassembler aligns and merges sequence fragments resulting from shotgun sequencing or gene transcripts fragments in order to reconstruct the original segment or gene (an overlap identity cutoff parameter of $80 \%$ has been used).

\section{CDNA references and genomes used in this study}

The C. jacchus, G. gorilla, H. sapiens, M. mulatta, M. murinus, N. leucogeny, O. garnettii, P. troglodytes, $P$. abelii, and T. syrichta cDNA references have been retrieved from the Ensembl [38] database. The sequencing of the C. sabaeus genome is currently in progress as part of an international collaborative effort at the Washington University Genome Center [39] and the draft scaffold genome release of this project has been used in this study. The draft assembly of the $M$. fascicularis genome used in this study is available through the ENA [69] database via accession numbers from FR874244 to FR874264 [5].

\section{ESTs alignment procedures}

Alignment of the ESTs on the cDNA references and on the $M$. fascicularis draft assembly genome has been done using the BLAST tool [70] (an Expect value cutoff parameter of 10 has been used). Alignment results have been filtered to only keep for each EST the best alignment for each species that has at least a support of $80 \%$ with the EST sequence. Alignment of the ESTs on the $C$. sabaeus draft scaffold genome has been performed using the CBRC-LAST [71] based online tool available on the website of the Washington University Genome Center [72].

\section{Functional pathway analysis}

The functional pathway analysis of the EST library has been performed using Ingenuity Pathways Analysis (IPA, Ingenuity ${ }^{\circ}$ Systems). IPA examines expressed genes in the context of known biological functions and pathways, mapping each gene identifier in a dataset to its corresponding molecule in the Ingenuity Pathways Knowledge Base (IPKB). P-values attributed to each pathway representing the statistical over-representation significance have been calculated by using the right-tailed Fisher's exact test and have been adjusted using the Benjamini-Hochberg Multiple Testing correction [73]. Over the 9,208 H. sapiens 
transcripts uniquely mapped by the 37,787 original ESTs, 8,579 have been identified by the IPKB and then used in the functional analysis.

\section{Quantification of the evolutionary relationships and construction of the phylogenetic trees}

Quantification of the evolutionary relationships among ESTs and EST mapped sequences has been performed using the Needleman-Wunsch multiple alignment algorithm [74]. Distance among sequences has been calculated using the Jukes-Cantor method [75] (maximum likelihood estimate) based on the NUC44 scoring matrix. Phylogenetic trees have been constructed by using the Unweighted Pair Group Method Average linking method (UPGMA, group average [76].

\section{Data accessibility}

The 37,787 ESTs are available on the dbEST [77] database via the library entry named " $C$. sabaeus PBMC EST Library" (accession: LIBEST_027323) and via Accession Numbers from JK088433 to JK126219. Each EST entry has been annotated with its associated contig (for assembled ESTs), its best high-quality mapped transcript with the corresponding gene for each cDNA reference, its 5 best mapped reads (when available) on the C. sabaeus draft scaffold genome, and the genomic position of its best alignment on the $M$. fascicularis draft assembly genome.

\section{Additional files}

Additional file 1: Figure S1. Number of AGM sequences published over the last years. Progression of AGM sequences published during the last two decades: this graph shows the number of AGM nucleotide sequences entered over each 5 year period in the NCBI nucleotide database with the number of sequences to be published in our EST library.

Additional file 2: Table S1. List of the highly covered Macaca mulatta ortholog transcripts. List of the 506 M. mulatta ortholog transcripts that have been highly covered an assembled EST. For each M. mulatta transcript, the Ensembl transcript Id, the gene symbol, and the assembled EST that mapped the transcript at least at $90 \%$ are given.

Additional file 3: Figure S2. Alignment details for the S100A4 gene. Alignment details for the S100 calcium binding protein A4 gene of the $M$. mulatta species (Ensembl ID: ENSMMUT00000015358). Assembled ESTs have been aligned at different positions of the gene: (1) Contig3147. Same legend and nomenclature as in Figure 3.

Additional file 4: Figure S3. Alignment details for the CD4 gene. Alignment details for the CD4 gene of the M. mulatta species (Ensembl ID: ENSMMUT00000018518). Assembled ESTs have been aligned at different positions of the gene: (1) PPOADA62YL02FM1. Same legend and nomenclature as in Figure 3.

Additional file 5: Figure S4. Alignment details for the IFNG gene. Alignment details for the Interferon-gamma gene of the M. mulatta species (Ensembl ID: ENSMMUT00000027007). Assembled ESTs have been aligned at different positions of the gene: (1) Contig3283 (2) PPOADA26YB24FM1. Same legend and nomenclature as in Figure 3.

Additional file 6: Figure S5. Alignment details for the IFNGR1 gene. Alignment details for the Interferon Gamma Receptor 1 gene of the $M$. mulatta species (Ensembl ID: ENSMMUTO0000016941). Assembled ESTs have been aligned at different positions of the gene: (1) Contig705 (2) PPOADA55YK24FM1. Same legend and nomenclature as in Figure 3.

Additional file 7: Figure S6. Alignment details for the IFNGR2 gene. Alignment details for the Interferon Gamma Receptor 2 gene of the $M$. mulatta species (Ensembl ID: ENSMMUG00000005508). Assembled ESTs have been aligned at different positions of the gene: (1)

PPOADA19YK11FM1. Same legend and nomenclature as in Figure 3.

Additional file 8: Figure S7. Representation of the "B cell receptor signaling" and "T cell receptor signaling" pathways. (A) Representation of the "B cell receptor signaling" pathway. (B) Representation of the "T cell receptor signaling" pathway. Same legend and nomenclature as in Figure 5.

Additional file 9: Figure S8. Representation of the "Role of NFAT in regulation of the immune response" and "Antigen presentation" pathways. (A) Representation of the "Role of NFAT in regulation of the immune response" pathway. (B) Representation of the "Antigen presentation" pathway. Same legend and nomenclature as in Figure 5.

Additional file 10: Figure S9. Representation of the "NF- $\kappa$ B activation by viruses" and "Induction of apoptosis by HIV-1" pathways. (A) Representation of the "NF- $\kappa$ B activation by viruses" pathway. (B) Representation of the "Induction of apoptosis by HIV-1" pathway. Same legend and nomenclature as in Figure 5.

Additional file 11: Table S2. Genomic distance matrix between the Chlorocebus sabaeus species and the old world monkeys and humans species. Genomic distance matrix computed between the ESTs of the original library and the mapped sequences of 7 old world monkey and human CDNA references restricted or not to specific regions of the transcripts ( $5^{\prime} \cup T R$, coding sequence, $3^{\prime} \cup T R$ ). For each comparing, the average multiple alignment score calculated over the commonly aligned sequences (c.a.s.) is given. Scores have been rescaled by multiplication by $10^{4}$.

Competing interests

The authors declare no competing interests.

\section{Authors' contributions}

NT - bioinformatics and analysis of the library, writing of ms; BJ - cell isolation and library preparation, writing of ms; PW, CD, CDS, JW - library construction and sequencing; $\mathrm{ABI}$ - candidate gene analysis; $\mathrm{MMT}, \mathrm{ABe}$ - project design, supervision, funding, writing of ms. All authors read and approved the final manuscript.

\section{Acknowledgements}

The authors are grateful to Brendan Bell for his critical comments on the manuscript. This work has been partially funded through the Agence Nationale de Recherches sur le SIDA et les hépatites virales (ANRS) and the Genopole Evry. The sequencing of the EST library has been funded through a Genoscope grant 2006/73.

\section{Author details}

${ }^{1}$ Institut des Hautes Études Scientifiques - Centre National de la Recherche Scientifique, Bures-sur-Yvette, France. ${ }^{2}$ Institut Pasteur, Unité de Régulation des Infections Rétrovirales, Paris, France. ${ }^{3}$ CEA, Institut de Génomique, Genoscope, Evry, France. ${ }^{4}$ Laboratoire d'Immunologie, CHU Rangueil, Toulouse, France. ${ }^{5}$ Vaccine Research Institute, Institut Mondor de Recherche Biomédicale, INSERM U955, Créteil, France.

Received: 2 April 2012 Accepted: 11 June 2012

Published: 22 June 2012

\section{References}

1. Sequencing TC, Consortium A: Initial sequence of the chimpanzee genome and comparison with the human genome. Nature 2005, 437(7055):69-87.

2. Gibbs RA, Rogers J, Katze MG, Bumgarner R, Weinstock GM, Mardis ER, Remington KA, Strausberg RL, Venter JC, Wilson RK, Batzer MA, Bustamante CD, Eichler EE, Hahn MW, Hardison RC, Makova KD, Miller W, Milosavljevic A, Palermo RE, Siepel A, Sikela JM, Attaway T, Bell S, Bernard KE, Buhay CJ, Chandrabose MN, Dao M, Davis C, Delehaunty KD, 
Ding Y, Dinh HH, Dugan-Rocha S, Fulton LA, Gabisi RA, Garner T, Godfrey J, Hawes AC, Hernandez J, Hines S, Holder M, Hume J, Jhangiani SN, Joshi V, Khan ZM, Kirkness EF, Cree A, Fowler RG, Lee S, Lewis LR, Li Z, Liu YS, Moore SM, Muzny D, Nazareth LV, Ngo DN, Okwuonu GO, Pai G, Parker D, Paul HA, Pfannkoch C, Pohl CS, Rogers YH, Ruiz SJ, Sabo A, Santibanez J, Schneider BW, Smith SM, Sodergren E, Svatek AF, Utterback TR, Vattathil S, Warren W, White CS, Chinwalla AT, Feng Y, Halpern AL, Hillier LW, Huang X, Minx P, Nelson JO, Pepin KH, Qin X, Sutton GG, Venter E, Walenz BP, Wallis JW, Worley KC, Yang SP, Jones SM, Marra MA, Rocchi M, Schein JE, Baertsch R, Clarke L, Csürös M, Glasscock J, Harris RA, Havlak P, Jackson AR, Jiang H, Liu Y, Messina DN, Shen Y, Song HXZ, Wylie T, Zhang L, Birney E, Han K, Konkel MK, Lee J, Smit AFA, Ullmer B, Wang H, Xing J, Burhans R, Cheng Z, Karro JE, Ma J, Raney B, She X, Cox MJ, Demuth JP, Dumas LJ, Han SG, Hopkins J, Karimpour-Fard A, Kim YH, Pollack JR, Vinar T, Addo-Quaye C,

Degenhardt J, Denby A, Hubisz MJ, Indap A, Kosiol C, Lahn BT, Lawson HA, Marklein A, Nielsen R, Vallender EJ, Clark AG, Ferguson B, Hernandez RD, Hirani K, Kehrer-Sawatzki H, Kolb J, Patil S, Pu LL, Ren Y, Smith DG, Wheeler DA, Schenck I, Ball EV, Chen R, Cooper DN, Giardine B, Hsu F, Kent WJ, Lesk A, Nelson DL, O'brien WE, Prüfer K, Stenson PD, Wallace JC, Ke H, Liu XM, Wang P, Xiang AP, Yang F, Barber GP, Haussler D, Karolchik D, Kern AD, Kuhn RM, Smith KE, Zwieg AS: Evolutionary and biomedical insights from the rhesus macaque genome. Science 2007, 316(5822):222-234

3. Locke DP, Hillier LW, Warren WC, Worley KC, Nazareth LV, Muzny DM, Yang SP, Wang Z, Chinwalla AT, Minx P, Mitreva M, Cook L, Delehaunty KD, Fronick C, Schmidt H, Fulton LA, Fulton RS, Nelson JO, Magrini V, Pohl C, Graves TA, Markovic C, Cree A, Dinh HH, Hume J, Kovar CL, Fowler GR, Lunter G, Meader S, Heger A, Ponting CP, Marques-Bonet T, Alkan C, Chen L, Cheng Z, Kidd JM, Eichler EE, White S, Searle S, Vilella AJ, Chen Y, Flicek P, Ma J, Raney B, Suh B, Burhans R, Herrero J, Haussler D, Faria R, Fernando O, Darré F, Farré D, Gazave E, Oliva M, Navarro A, Roberto R, Capozzi O, Archidiacono N, Valle GD, Purgato S, Rocchi M, Konkel MK, Walker JA, Ullmer B, Batzer MA, Smit AFA, Hubley R, Casola C, Schrider DR, Hahn MW, Quesada V, Puente XS, Ordoñez GR, López-Otín C, Vinar T, Brejova B, Ratan A, Harris RS, Miller W, Kosiol C, Lawson HA, Taliwal V, Martins AL, Siepel A, RoyChoudhury A, Ma X, Degenhardt J,

Bustamante CD, Gutenkunst RN, Mailund T, Dutheil JY, Hobolth A, Schierup MH, Ryder OA, Yoshinaga Y, De Jong PJ, Weinstock GM, Rogers J, Mardis ER, Gibbs RA, Wilson RK: Comparative and demographic analysis of orang-utan genomes. Nature 2011, 469(7331):529-533.

4. Yan G, Zhang G, Fang X, Zhang Y, Li C, Ling F, Cooper DN, Li Q, Li Y, Van Gool AJ, Du H, Chen J, Chen R, Zhang P, Huang Z, Thompson JR, Meng Y, Bai Y, Wang J, Zhuo M, Wang T, Huang Y, Wei L, Li J, Wang Z, Hu H, Yang P, Le L, Stenson PD, Li B, Liu X, Ball EV, An N, Huang Q, Zhang Y, Fan W, Zhang X, Li Y, Wang W, Katze MG, Su B, Nielsen R, Yang H, Wang J, Wang $X$, Wang J: Genome sequencing and comparison of two nonhuman primate animal models, the cynomolgus and Chinese rhesus macaques. Nat Biotechnol 2011, 29(11):1-86.

5. Ebeling M, Küng E, See A, Broger C, Steiner G, Berrera M, Heckel T, Iniguez L, Albert T, Schmucki R, et al: Genome-based analysis of the nonhuman primate Macaca fascicularis as a model for drug safety assessment. Genome Research 2011, 21(10):1746-1756.

6. Bosinger SE, Johnson ZP, Silvestri G: Primate genomes for biomedicine. Nat Biotechnol 2011, 29(11):983-984.

7. Bosinger S, Jacquelin B, Benecke A, Silvestri G, Müller-Trutwin M: Systems biology of natural simian immunodeficiency virus infections. Current Opinion in HIV and AIDS 2012, 7(1):71-78.

8. Jentsch JD, Redmond DE, Elsworth JD, Taylor JR, Youngren KD, Roth RH: Enduring cognitive deficits and cortical dopamine dysfunction in monkeys after long-term administration of phencyclidine. Science 1997, 277(5328):953-955.

9. Taylor JR, Elsworth JD, Roth RH, Sladek JR, Redmond DE: Severe long-term 1-methyl-4-phenyl-1,2,3,6-tetrahydropyridine-induced parkinsonism in the vervet monkey (Cercopithecus aethiops sabaeus). Neuroscience 1997, 81(3):745-755.

10. Cook JJ, Sitko GR, Bednar B, Condra C, Mellott MJ, Feng DM, Nutt RF, Shafer JA, Gould RJ, Connolly TM: An Antibody Against the Exosite of the Cloned Thrombin Receptor Inhibits Experimental Arterial Thrombosis in the African Green Monkey. Circulation 1995, 91(12):2961-2971.
11. Ohno T, Wang X, Kurashima J, Saijo-Kurita K, Hirono M: A novel Vero cell line for use as a mammalian host-vector system in serum-free medium. Cytotechnology 1991, 7(3):165-172.

12. Vincent-Falquet JC, Peyron L, Souvras M, Moulin JC, Tektoff J, Patet J: Qualification of working cell banks for the Vero cell line to produce licensed human vaccines. Developments in Biological Standardization 1989, 70:153-156

13. Almeida J, Hill C, Cole K: Authentication of African green monkey cell lines using human short tandem repeat markers. BMC Biotechnology 2011, 11:102.

14. Ward KW, Coon DJ, Magiera D, Bhadresa S, Nisbett E, Lawrence MS: Exploration of the African green monkey as a preclinical pharmacokinetic model: intravenous pharmacokinetic parameters. Drug metabolism and disposition the biological fate of chemicals 2008, 36(4):715-720.

15. Bossart KN, Geisbert TW, Feldmann H, Zhu Z, Feldmann F, Geisbert JB, Yan L, Feng YR, Brining D, Scott D, Wang Y, Dimitrov AS, Callison J, Chan YP, Hickey AC, Dimitrov DS, Broder CC, Rockx B: A neutralizing human monoclonal antibody protects african green monkeys from hendra virus challenge. Science translational medicine 2011, 3(105):105ra103.

16. Weiss WJ, Murphy T, Lynch ME, Frye J, Buklan A, Gray B, Lenoy E, Mitelman S, O'Connell J, Quartuccio S, et al: Inhalation efficacy of RFI-641 in an African green monkey model of RSV infection. Journal of Medical Primatology 2003, 32(2):82-88.

17. Swearengen J: Biodefense: research methodology and animal models. Boca Raton, (FL): CRC Press; 2006.

18. Ohta Y, Masuda T, Tsujimoto H, Ishikawa K, Kodama T, Morikawa S, Nakai M, Honjo S, Hayami M: Isolation of simian immunodeficiency virus from African green monkeys and seroepidemiologic survey of the virus in various non-human primates. International journal of cancer Journal international du cancer 1988, 41:115-122.

19. Liovat AS, Jacquelin B, Ploquin MJ, Barré-Sinoussi F, Müller-Trutwin MC African non human primates infected by SIV - why don't they get sick? Lessons from studies on the early phase of non-pathogenic SIV infection. Current HIV Research 2009, 7:39-50.

20. Sodora DL, Allan JS, Apetrei C, Brenchley JM, Douek DC, Else JG, Estes JD, Hahn r, H, Hirsch VM, Kaur A, Kirchhoff F, Muller-Trutwin M, Pandrea I, Schmitz JE, Silvestri G: Toward an AIDS vaccine: lessons from natural simian immunodeficiency virus infections of African nonhuman primate hosts. Nat Med 2009, 15(8):861-865

21. Jacquelin B, Zahn RC, Barré-Sinoussi F, Schmitz JE, Kaur A Müller-Trutwin MC: Natural SIV Infection: Immunological Aspects. In Models of Protection Against HIV/SIV: How some Humans and Many Monkeys have Learned to deal Successfully with HIV \& SIV. Edited by Pancino G, Silvestri G, Fowke K. New York: Academic Press (Elsevier):47-80.

22. Diop OM, Gueye A, Dias-Tavares M, Kornfeld C, Faye A, Ave P, Huerre M, Corbet S, Barre-Sinoussi F, Müller-Trutwin MC: High Levels of Viral Replication during Primary Simian Immunodeficiency Virus SIVagm Infection Are Rapidly and Strongly Controlled in African Green Monkeys. Journal of Virology 2000, 74(16):7538-7547.

23. Goldstein S, Ourmanov I, Brown CR, Beer BE, Elkins WR, Plishka R, Buckler-White A, Hirsch VM: Wide range of viral load in healthy african green monkeys naturally infected with simian immunodeficiency virus. Journal of Virology 2000, 74(24):11744-11753.

24. Gueye A, Diop OM, Ploquin MJY, Kornfeld C, Faye A, Cumont MC, Hurtrel B, Barré-Sinoussi F, Müller-Trutwin MC: Viral load in tissues during the early and chronic phase of non-pathogenic SIVagm infection. Journal of Medical Primatology 2004, 33(2):83-97.

25. Kornfeld C, Ploquin MJY, Pandrea I, Faye A, Onanga R, Apetrei C, Poaty-Mavoungou V, Rouquet P, Estaquier J, Mortara L, et al: Antiinflammatory profiles during primary SIV infection in African green monkeys are associated with protection against AIDS. Journal of Clinical Investigation 2005, 115(4):1082-1091.

26. Pandrea I, Kornfeld C, Ploquin MJY, Apetrei C, Faye A, Rouquet $P$, Roques $P$, Simon F, Barré-Sinoussi F, Müller-Trutwin MC, Diop OM: Impact of viral factors on very early in vivo replication profiles in simian immunodeficiency virus SIVagm-infected African green monkeys. Journal of Virology 2005, 79(10):6249-6259.

27. Schmitz JE, Zahn RC, Brown CR, Rett MD, Li M, Tang H, Pryputniewicz S, Byrum RA, Kaur A, Montefiori DC, Allan JS, Goldstein S, Hirsch VM: 
Inhibition of Adaptive Immune Responses Leads to a Fatal Clinical Outcome in SIV-Infected Pigtailed Macaques but Not Vervet African Green Monkeys. PLoS Pathogens 2009, 5(12):14.

28. Pandrea I, Apetrei C, Dufour J, Dillon N, Barbercheck J, Metzger M, Jacquelin B, Bohm R, Marx PA, Barre-Sinoussi F, Hirsch VM, Müller-Trutwin MC, Lackner AA, Veazey RS: Simian Immunodeficiency Virus SIVagm.sab Infection of Carribean African Green Monkeys: a New Model for the Study of SIV Pathogenesis in Natural Hosts. Journal of Virology 2006, 80(10):4858-4867.

29. Jacquelin B, Mayau V, Targat B, Liovat AS, Kunkel D, Petitjean G, Dillies MA, Roques P, Butor C, Silvestri G, Giavedoni LD, Lebon P, Barré-Sinoussi F, Benecke A, Müller-Trutwin MC: Nonpathogenic SIV infection of African green monkeys induces a strong but rapidly controlled type I IFN response. Journal of Clinical Investigation 2009, 119(12):3544-3555.

30. Lederer S, Favre D, Walters KA, Proll S, Kanwar B, Kasakow Z, Baskin CR, Palermo R, McCune JM, Katze MG: Transcriptional Profiling in Pathogenic and Non-Pathogenic SIV Infections Reveals Significant Distinctions in Kinetics and Tissue Compartmentalization. PLOS Pathogens 2009, 5(2):15.

31. Fomsgaard A, Müller-Trutwin MC, Diop O, Hansen J, Mathiot C, Corbet $S$, Barré-Sinoussi F, Allan JS: Relation between phylogeny of African green monkey CD4 genes and their respective simian immunodeficiency virus genes. Journal of Medical Primatology 1997, 26(3):120-128.

32. Kuhmann SE, Madani N, Diop OM, Platt EJ, Morvan J, Müller-Trutwin MC, Barré-Sinoussi F, Kabat D: Frequent substitution polymorphisms in African green monkey CCR5 cluster at critical sites for infections by simian immunodeficiency virus SIVagm, implying ancient virus-host coevolution. Journal of Virology 2001, 75(18): 8449-8460

33. Müller-Trutwin MC, Corbet S, Hansen J, Georges-Courbot MC, Diop O, Rigoulet J, Barré-Sinoussi F, Fomsgaard A: Mutations in CCR5-coding sequences are not associated with SIV carrier status in African nonhuman primates. AIDS Research and Human Retroviruses 1999, 15(10):931-939.

34. Hassan B (Ed): Genes Expressed in Specific Areas of the Human Fetal Cerebral Cortex Display Distinct Patterns of Evolution. PLOS ONE 2011, 6(3):13.

35. Sayah DM, Sokolskaja E, Berthoux L, Luban J: Cyclophilin A retrotransposition into TRIM5 explains owl monkey resistance to HIV-1. Nature 2004, 430(6999):569-573.

36. Jacquelin B, Mayau V, Brysbaert G, Regnault R, Diop OM Arenzana-Seisdedos F, Rogge L, Coppee JY, Barre-Sinoussi F, Benecke A, Müller-Trutwin MC: Long oligonucleotide microarrays for African green monkey gene expression profile analysis. Faseb Journal 2007, 21(12):3262.

37. Benson DA, Karsch-Mizrachi I, Lipman DJ, Ostell J, Wheeler DL: GenBank: update. Nucleic Acids Res 2004, 32(Database issue):D23-D26.

38. Hubbard T, Barker D, Birney E, Cameron G, Chen Y, Clark L, Cox T, Cuff J, Curwen V, Down T, Durbin R, Eyras E, Gilbert J, Hammond M, Huminiecki L, Kasprzyk A, Lehvaslaiho H, Lijnzaad P, Melsopp C, Mongin E, Pettett R, Pocock M, Potter S, Rust A, Schmidt E, Searle S, Slater G, Smith J, Spooner W, Stabenau A, Stalker J, Stupka E, Ureta-Vidal A, Vastrik I, Clamp M: The Ensembl genome database project. Nucleic Acids Res 2002, 30:38-41.

39. Integrated Vervet/AGM Research \& Resources. [http://www genomequebec.mcgill.ca/compgen/vervet_research/ genomics_genetics/].

40. Lovatt M, Yang TH, Stauss HJ, Fisher AG, Merkenschlager M: Different doses of agonistic ligand drive the maturation of functional CD4 and CD8 T cells from immature precursors. European Journal of Immunology 2000, 30(2):371-381.

41. Wang $Y$, Gao B, Tsan MF: Induction of cytokines by heat shock proteins and concanavalin A in murine splenocytes. Cytokine 2005, 32(3-4):149-154.

42. Jentsch JD, Redmond DE, Elsworth JD, Taylor JR, Youngren KD, Roth RH: Enduring cognitive deficits and cortical dopamine dysfunction in monkeys after long-term administration of phencyclidine. Science 1997, 277(5328):953-955.

43. Taylor JR, Elsworth JD, Roth RH, Sladek JR, Redmond DE: Severe long-term 1-methyl-4-phenyl-1,2,3,6-tetrahydropyridine-induced parkinsonism in the vervet monkey (Cercopithecus aethiops sabaeus). Neuroscience 1997, 81(3):745-755.

44. Ohno T, Wang X, Kurashima J, Saijo-Kurita K, Hirono M: A novel Vero cell line for use as a mammalian host-vector system in serum-free medium. Cytotechnology 1991, 7(3):165-172.

45. Cook JJ, Sitko GR, Bednar B, Condra C, Mellott MJ, Feng DM, Nutt RF, Shafer JA, Gould TM Robert J, Connolly: An Antibody Against the Exosite of the Cloned Thrombin Receptor Inhibits Experimental Arterial Thrombosis in the African Green Monkey. Circulation 1995, 91(12):2961-2971

46. Vincent-Falquet JC, Peyron L, Souvras M, Moulin JC, Tektoff J, Patet J: Qualification of working cell banks for the Vero cell line to produce licensed human vaccines. Developments in Biological Standardization 1989, 70:153-156.

47. Almeida JL, Hill CR, Cole KD: Authentication of African green monkey cell lines using human short tandem repeat markers. $B M C$ Biotechnology 2011, 11:102

48. Ward KW, Coon DJ, Magiera D, Bhadresa S, Nisbett E, Lawrence MS: Exploration of the African green monkey as a preclinical pharmacokinetic model: intravenous pharmacokinetic parameters. Drug metabolism and disposition the biological fate of chemicals 2008, 36(4):715-720.

49. Bossart KN, Geisbert TW, Feldmann H, Zhu Z, Feldmann F, Geisbert JB, Yan L, Feng YR, Brining D, Scott D, et al: A neutralizing human monoclonal antibody protects african green monkeys from hendra virus challenge. Science translational medicine 2011, 3(105):105ra103.

50. Weiss WJ, Murphy T, Lynch ME, Frye J, Buklan A, Gray B, Lenoy E, Mitelman S, O'Connell J, Quartuccio S, et al: Inhalation efficacy of RFI-641 in an African green monkey model of RSV infection. Journal of Medical Primatology 2003, 32(2):82-88.

51. Redmond DE, Bjugstad KB, Teng YD, Ourednik V, Ourednik J, Wakeman DR, Parsons XH, Gonzalez R, Blanchard BC, Kim SU, et al: From the Cover: Behavioral improvement in a primate Parkinson's model is associated with multiple homeostatic effects of human neural stem cells. Proceedings of the National Academy of Sciences 2007, 104(29):12175-12180

52. Lemere CA, Beierschmitt A, Iglesias M, Spooner ET, Bloom JK, Leverone JF, Zheng JB, Seabrook TJ, Louard D, Li D, et al: Alzheimer's disease abeta vaccine reduces central nervous system abeta levels in a non-human primate, the Caribrefn vervet. The American journal of pathology 2004, 165:283-297.

53. Sodora DL, Allan JS, Apetrei C, Brenchley JM, Douek DC, Else JG, Estes JD, Hahn $\mathrm{rH}$, Hirsch VM, Kaur A, et al: Toward an AIDS vaccine: lessons from natural simian immunodeficiency virus infections of African nonhuman primate hosts. Nat Med 2009, 15(8): 861-865.

54. Pesole G, Mignone F, Gissi C, Grillo G, Licciulli F, Liuni S: Structural and functional features of eukaryotic mRNA untranslated regions. Gene 2001, 276(1-2):73-81.

55. Hellmann I, Zollner S, Enard W, Ebersberger I, Nickel B, Paabo S: Selection on Human Genes as Revealed by Comparisons to Chimpanzee cDNA. Genome Research 2003, 13(5):831-837.

56. Osada N, Hirata M, Tanuma R, Kusuda J, Hida M, Suzuki Y, Sugano S, Gojobori T, Shen CKJ, Wu Cl, Hashimoto K: Substitution Rate and Structural Divergence of 5'UTR Evolution: Comparative Analysis Between Human and Cynomolgus Monkey cDNAs. Molecular Biology and Evolution October 2005, 22(10):1976-1982.

57. Crawford DL, Powers DA: Molecular basis of evolutionary adaptation at the lactate dehydrogenase-B locus in the fish Fundulus heteroclitus. Proceedings of the National Academy of Sciences of the United States of America 1989, 86(23):9365-9369.

58. Gilad Y, Oshlack A, Smyth GK, Speed TP, White KP: Expression profiling in primates reveals a rapid evolution of human transcription factors. Nature 2006, 440(7081):242-245.

59. Barreiro LB, Marioni JC, Blekhman R, Stephens M, Gilad Y: Functional Comparison of Innate Immune Signaling Pathways in Primates. PLOS Genetics 2010, 6(12):13.

60. Liu M, Guo S, Hibbert JM, Jain V, Singh N, Wilson NO, Stiles JK CXCL10/IP-10 in infectious diseases pathogenesis and potential therapeutic implications. Cytokine growth factor reviews 2011, 22(3): $121-130$ 
61. Perry AK, Chen G, Zheng D, Tang H, Cheng G: The host type I interferon response to viral and bacterial infections. Cell Research 2005, 15(6):407-22.

62. Hu X, Ivashkiv LB: Cross-regulation of signaling pathways by interferon-gamma: implications for immune responses and autoimmune diseases. Immunity 2009, 31(4):539-550.

63. Manry J, Laval G, Patin E, Fornarino S, Tichit M, Bouchier C, Barreiro LB, Quintana-Murci L: Evolutionary genetics evidence of an essential, nonredundant role of the IFN-? pathway in protective immunity. Human Mutation 2011, 32(6):633-642.

64. Casrouge A, Decalf J, Ahloulay M, Lababidi C, Mansour H, Vallet-Pichard A, Mallet V, Mottez E, Mapes J, Fontanet A, et al: Evidence for an antagonist form of the chemokine CXCL10 in patients chronically infected with HCV. Journal of Clinical Investigation 2011, 121:308-317.

65. Bunting MD, Comerford I, McColl SR: Finding their niche: chemokines directing cell migration in the thymus. Immunology and Cell Biology 2011, 89(2):185-196.

66. Mandl JN, Barry AP, Vanderford TH, Kozyr N, Chavan R, Klucking S, Barrat FJ, Coffman RL, Staprans SI, Feinberg MB: Divergent TLR7 and TLR9 signaling and type I interferon production distinguish pathogenic and nonpathogenic AIDS virus infections. Nat Med 2008, 14(10):1077-1087.

67. Rice P: EMBOSS: The European Molecular Biology Open Software Suite. Trends in Genetics 2000, 16(6):276-277.

68. Masoudi-Nejad A, Tonomura K, Kawashima S, Moriya Y, Suzuki M, Itoh M, Kanehisa M, Endo T, Goto S: EGassembler: online bioinformatics service for large-scale processing, clustering and assembling ESTs and genomic DNA fragments. Nucleic Acids Res 2006, 34(Web Server issue):W459-W462.

69. Leinonen R, Akhtar R, Birney E, Bower L, Cerdeno-Tárraga A, Cheng Y, Cleland I, Faruque N, Goodgame N, Gibson R, Hoad G, Jang M, Pakseresht N, Plaister S, Radhakrishnan R, Reddy K, Sobhany S, Ten Hoopen P, Vaughan R, Zalunin V, Cochrane G: The European Nucleotide Archive. Nucleic Acids Res 2011, 39(Database issue):D28-31

70. Altschul SF, Gish W, Miller W, Myers EW, Lipman DJ: Basic local alignment search tool. J Mol Biol 1990, 215(3):403-410.

71. Kiełbasa SM, Wan R, Sato K, Horton P, Frith MC: Adaptive seeds tame genomic sequence comparison. Genome Research 2011, 21(3):487-493.

72. Integrated Vervet/AGM Research \& Resources. [http://www. genomequebec.mcgill.ca/compgen/vervet_research/cgi-bin/ vervet_seq_db.pl].

73. Benjamini Y, Hochberg Y: Controlling the False Discovery Rate: A Practical and Powerful Approach to Multiple Testing. Journal of the Royal Statistical Society. Series B (Methodological) 1995, 57:289-300.

74. Needleman SB: Wunsch CD: A general method applicable to the search for similarities in the amino acid sequence of two proteins. Mol Biol 1970, 48(3):443-453.

75. Jukes TH, Cantor CR: Evolution of Protein Molecules. New York: Academy Press; 1969.

76. Sokal RR, Michener CD: A statistical method for evaluating systematic relationships. University of Kansas Scientific Bulletin 1958, 28(22):1409-1438.

77. Boguski MS, Lowe TM: Tolstoshev CM: dbEST-database for "expressed sequence tags". Nat Genet 1993, 4(4):332-333.

Submit your next manuscript to BioMed Central and take full advantage of:

- Convenient online submission

- Thorough peer review

- No space constraints or color figure charges

- Immediate publication on acceptance

- Inclusion in PubMed, CAS, Scopus and Google Scholar

- Research which is freely available for redistribution

Submit your manuscript at www.biomedcentral.com/submit
Ciomed Central 